\title{
Accounting for inter-correlation between enzyme abundance: a simulation study to assess implications on global sensitivity analysis within physiologically-based pharmacokinetics
}

Dol:

10.1007/s10928-019-09627-6

Document Version

Accepted author manuscript

Link to publication record in Manchester Research Explorer

Citation for published version (APA):

Melillo, N., Darwich, A. S., Magni, P., \& Rostami-hodjegan, A. (2019). Accounting for inter-correlation between enzyme abundance: a simulation study to assess implications on global sensitivity analysis within physiologicallybased pharmacokinetics. Journal of pharmacokinetics and pharmacodynamics. https://doi.org/10.1007/s10928019-09627-6

Published in:

Journal of pharmacokinetics and pharmacodynamics

\section{Citing this paper}

Please note that where the full-text provided on Manchester Research Explorer is the Author Accepted Manuscript or Proof version this may differ from the final Published version. If citing, it is advised that you check and use the publisher's definitive version.

\section{General rights}

Copyright and moral rights for the publications made accessible in the Research Explorer are retained by the authors and/or other copyright owners and it is a condition of accessing publications that users recognise and abide by the legal requirements associated with these rights.

\section{Takedown policy}

If you believe that this document breaches copyright please refer to the University of Manchester's Takedown Procedures [http://man.ac.uk/04Y6Bo] or contact uml.scholarlycommunications@manchester.ac.uk providing relevant details, so we can investigate your claim.

\section{OPEN ACCESS}




\section{Journal of Pharmacokinetics and Pharmacodynamics \\ Accounting for Inter-correlation between Enzyme Abundance: A Simulation Study to Assess Implications on Global Sensitivity Analysis within Physiologically-Based Pharmacokinetics \\ --Manuscript Draft--}

\begin{tabular}{|c|c|}
\hline Manuscript Number: & JOPA-D-18-00119R2 \\
\hline Article Type: & S.I. : Tribute to Panos Macheros \\
\hline Keywords: & $\begin{array}{l}\text { Enzymes; correlation; simulation; physiologically based pharmacokinetics; global } \\
\text { sensitivity analysis; regression }\end{array}$ \\
\hline Corresponding Author: & $\begin{array}{l}\text { Nicola Melillo } \\
\text { Universita degli Studi di Pavia } \\
\text { Pavia, Pavia ITALY }\end{array}$ \\
\hline \multicolumn{2}{|l|}{$\begin{array}{l}\text { Corresponding Author Secondary } \\
\text { Information: }\end{array}$} \\
\hline First Author: & Nicola Melillo \\
\hline \multicolumn{2}{|l|}{ First Author Secondary Information: } \\
\hline \multirow[t]{4}{*}{ Order of Authors: } & Nicola Melillo \\
\hline & Adam Darwich \\
\hline & Paolo Magni \\
\hline & Amin Rostami-Hodjegan \\
\hline
\end{tabular}




\section{Response to the reviewers}

\section{Editor}

The authors have responded to the majority of issues. However, the manuscript would likely benefit from some additional text that is related to the first response to reviewer \#1 (regarding interpretability and the incorporation of known underlying correlations as a means of evaluating the impact and also preserving known information in the system) and comment \#4 from the same reviewer that is along similar lines.

\section{Response}

Thank you for the observation and recommendation. We have taken your suggestion and modified a paragraph in the Discussion (page 18, line 8) to reflect the comments we made in our response to the reviewer. Moreover, we added two sentences in the Conclusions (page 20, line 2) to give cautionary measures and prevent 'over-interpretation' of the results from current limited investigation.

p.18: "The results of this analysis show the necessity of considering the correlation between enzymatic expressions in physiological model when confidence in biological evidence for such correlations is high. Otherwise, there is a risk of underestimating the population variability or overestimate the effect of DDI (though this is shown for direct correlations of enzymes and the reverse could be true if the enzyme abundances were inversely related). To remain true to the knowledge of the system, PBPK platforms should not ignore known correlations of any of the model parameters. However, one has to consider that in a whole body PBPK model (unlike the minimal model used in our investigation), it is likely that some of our findings might be mitigated due lack of dominance of parameters that we intentionally selected in this study. Our study considered some conditions (e.g., equal intrinsic clearance between two correlated enzymes) which were in favour of propagating the inter-correlation effect to make the point and these may not be the case at the presence of multiple parameters variabilities and correlations".

p.19: "Our work informs the debate that is needed to take place in considering recent data generated by the proteomic analysis and regulatory interest in the use of sensitivity analysis in PBPK. We fully encourage continuation of investigation on inter-correlation not only for protein expressions relevant to drug disposition, but also for the various attributes of the gastro-intestinal tract where many potential/likely correlations related to physiology and biology are not fully considered in PBPK models yet. Inter-correlations may not be relevant when considering the model for an average individual, however, they are pertinent to all aspects of population-based projections from mechanistic models within pharmacometrics and systems pharmacology modelling". 


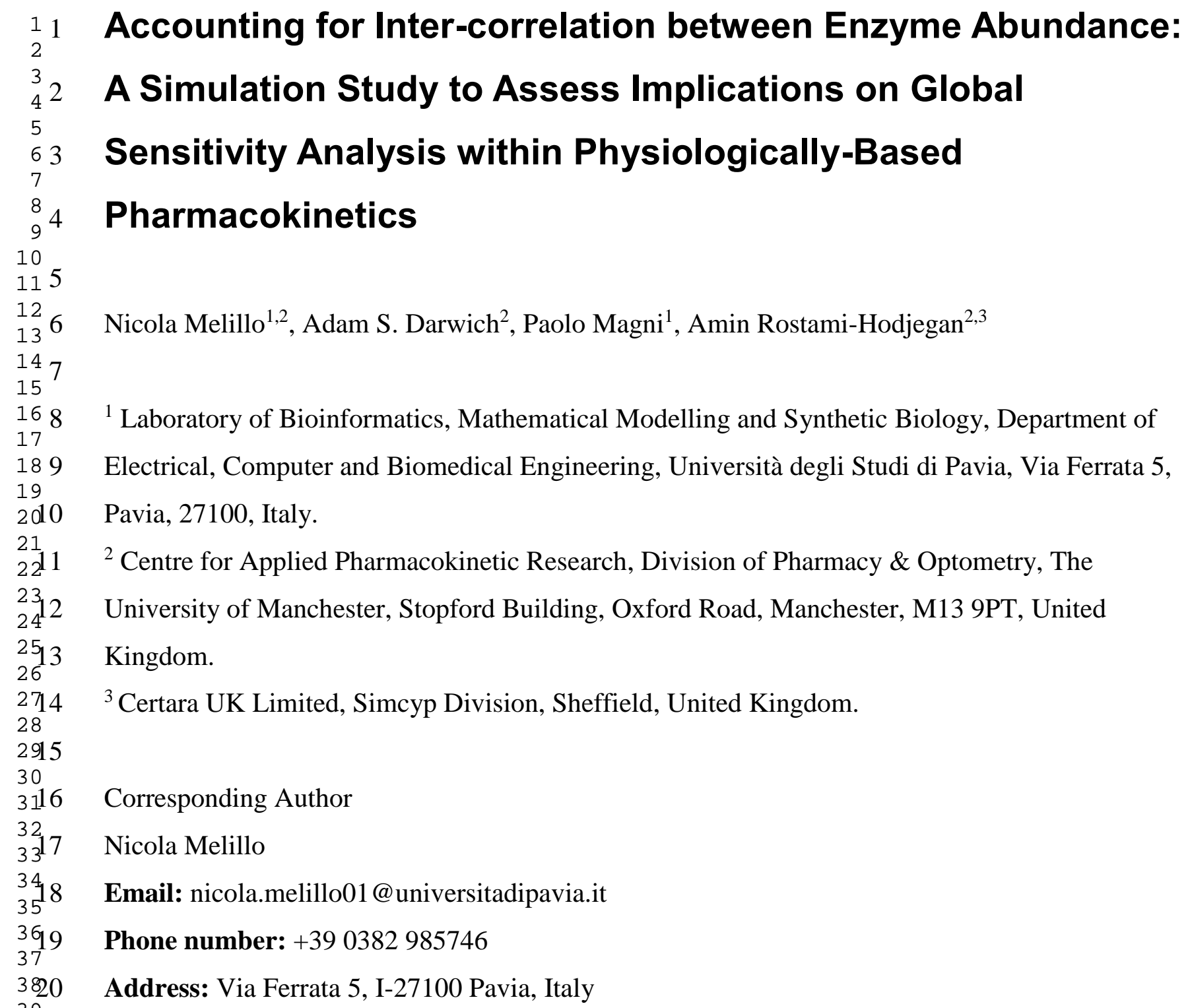

Nicola Melillo ${ }^{1,2}$, Adam S. Darwich ${ }^{2}$, Paolo Magni ${ }^{1}$, Amin Rostami-Hodjegan $^{2,3}$

${ }^{1}$ Laboratory of Bioinformatics, Mathematical Modelling and Synthetic Biology, Department of Electrical, Computer and Biomedical Engineering, Università degli Studi di Pavia, Via Ferrata 5, Pavia, 27100, Italy.

${ }^{2}$ Centre for Applied Pharmacokinetic Research, Division of Pharmacy \& Optometry, The University of Manchester, Stopford Building, Oxford Road, Manchester, M13 9PT, United Kingdom.

${ }^{3}$ Certara UK Limited, Simcyp Division, Sheffield, United Kingdom.

Corresponding Author

Nicola Melillo

Email: nicola.melillo01@universitadipavia.it

Phone number: +390382985746

Address: Via Ferrata 5, I-27100 Pavia, Italy 


\section{Abstract}

Physiologically based pharmacokinetic (PBPK) models often include several sets of correlated parameters, such as organ volumes and blood flows. Because of recent advances in proteomics, it has been demonstrated that correlations are also present between abundances of drug-metabolising enzymes in the liver. As the focus of population PBPK has shifted the emphasis from the average individual to theoretically conceivable extremes, reliable estimation of the extreme cases has become paramount.

We performed a simulation study to assess the impact of the correlation between the abundances of two enzymes on the pharmacokinetics of drugs that are substrate of both, under assumptions of presence or lack of such correlations. We considered three semi-physiological models representing the cases of: 1) intravenously administered drugs metabolised by two enzymes expressed in the liver; 2) orally administered drugs metabolised by CYP3A4 expressed in the liver and gut wall; 3) intravenously administered drugs that are substrates of CYP3A4 and OATP1B1 in the liver. Finally, the impact of considering or ignoring correlation between enzymatic abundances on global sensitivity analysis (GSA) was investigated using variance based GSA on a reduced PBPK model for repaglinide, substrate of CYP3A4 and CYP2C8.

Implementing such correlations can increase the confidence interval for population pharmacokinetic parameters (e.g., AUC, bioavailability) and impact the GSA results. Ignoring these correlations could lead to the generation of implausible parameters combinations and to an incorrect estimation of pharmacokinetic related parameters. Thus, known correlations should always be considered in building population PBPK models.

\section{Keywords}

Enzymes, correlation, simulation, physiologically based pharmacokinetics, global sensitivity analysis. 


\section{Introduction}

In the recent European Medicines Agency (EMA) draft guidance on the qualification and reporting of physiologically based pharmacokinetic (PBPK) models, the need to assess the biological plausibility and validity of model parameter values was highlighted. Further, EMA encouraged PBPK platforms to evolve with new published data [1]. In order to simulate the variability in pharmacokinetics of a given drug in a given population, a set of individuals are generated by sampling model parameter values within a predefined space (e.g., liver volume and blood flow) [2, 3]. In PBPK simulations for large populations of virtual patients, if during the process of assigning system parameters, the correlations between various anatomical, physiological and biological attributes are ignored, it is possible to generate "implausible combinations of parameters". This could lead to an erroneous estimation of the interindividual variability of the main pharmacokinetic parameters, such as clearance $[4,5]$.

Accordingly, most PBPK models implement, for example, the known correlation between organ volumes and blood flows $[3,6]$. However, there are other physiological and biological components of the system with known degrees of correlation which are not considered in the development of virtual populations. These include enzyme expressions in various organs and tissues. Recently, novel techniques in quantitative proteomics has made possible the reliable quantification of multiple enzyme and transporter expressions in the same experiment and sample. This allows robust measures of correlations between proteins $[7,8]$. For example, it has been shown that various Cytochrome P450 (CYPs) enzymes and UDP-glucuronosyltransferases (UGT) are correlated [9]. Recent work has demonstrated that including the correlation between hepatic CYP3A4 and CYP2C8 in PBPK modelling of repaglinide, leads to improved performance in predicting interindividual variability in drug clearance and the magnitude of metabolic drug-drug interactions (DDIs), as compared to the same PBPK predictions without correlation [8]. While the correlation between hepatic CYPs and UGTs has been robustly assessed, that between CYP3A4 in liver and gut wall remains controversial: some work suggests its absence [10], while other work suggests its presence [11]. Moreover, to our knowledge, evidence in the literature regarding any correlation between enzyme and transporter expressions and their relevance are still insufficient [8], however, this type of correlation might be possible (internal unpublished data).

In this context, simulation studies using mathematical models, may be informative in highlighting possible correlations that may impact the pharmacokinetics (PK) of drugs and, by extension, may inform experimental design. The aim of our work was to perform a simulation study in order to theoretically assess the impact of the correlation between the expressions of two enzymes, under 
different conditions, on the PK of drugs that are substrates of both enzymes. For this purpose, we considered three simple compartmental semi-physiological models representing the cases of: 1) intravenously (IV) administered drugs metabolised by two enzymes expressed in the liver; 2) orally administered drugs metabolised by CYP3A4 expressed in the gut wall and liver; 3) IV administered drugs that are substrates of CYP3A4 and OATP1B1, both expressed in the liver. For each of these models we tested the impact of correlation between the expression of the two enzymes with respect to the case of absence of correlation. We choose to use simple compartmental models in order to highlight the correlation effect (if present), while limiting the effect of confounding variables and thus, simplifying the interpretation of the results.

Finally, the EMA report highlighted the importance of performing a sensitivity analysis "for all the parameters that are likely to markedly influence the outcome of simulated pharmacokinetics and/or the model application" [1]. Hence, we assessed how the correlation between enzymatic abundances impacts the results and interpretation of sensitivity analysis [4]. For this purpose, we performed global sensitivity analysis (GSA) [12] on a semi-physiological model describing repaglinide pharmacokinetics after IV infusion. Repaglinide is a substrate of CYP3A4 and CYP2C8, where the abundances of these two enzymes have been shown to be correlated in the liver [9]. Different degrees of correlation between the two enzymes were tested in terms of their impact on the GSA results. As suggested in Saltelli et al., [13], we choose to express the correlation between the two enzymes by using an explicit relationship (e.g., linear regression) with the addition of an independent noise term and then performed a GSA on the uncorrelated parameters. The technique that we choose to use to perform the GSA was the variance based method [13-15].

\section{Methods}

A simulation study was performed to assess the effect of the correlation between enzymatic expressions, in different situations, on the PK of drugs with different intrinsic clearances. Then, the impact of correlation between hepatic CYP3A4 and CYP2C8 expressions on the results of a variance based GSA of a semi-physiological model describing repaglinide PK after IV infusion was assessed. The model parameter values that are considered fixed are reported in Table 1, the distributions of the enzyme concentrations are reported in Table 2 and the parameters related to repaglinide metabolism and distribution are given in Table 3 . The analysis was performed using MATLAB R2017b [16] on a 64-bit computer configured with Intel® Core $^{\mathrm{TM}}$ i7-7700 @ 3.60 GHz x 8 processor, running Ubuntu 16.04 LTS. 


\section{Simulation study}

\section{Two enzymes in the liver}

A semi-physiological two-compartmental model was developed to simulate IV administration at an arbitrary dose of $1 \mathrm{mg}$ of drug. The model, represented in Figure 1a, is composed of one central compartment and one compartment representing the liver. Drug metabolism occurs in the liver and depends on the activity of two different enzymes, namely enzyme $1\left(E_{1}\right)$ and enzyme $2\left(E_{2}\right)$, with equal intrinsic clearances. Model equations are shown in (1).

$$
\begin{aligned}
\frac{d x_{c}}{d t} & =\frac{Q_{\text {liv,art }}}{V_{\text {liv }}} x_{\text {liv }}-\frac{Q_{\text {liv, art }}}{V_{c}} x_{c} \\
\frac{d x_{\text {liv }}}{d t} & =\frac{Q_{\text {liv, art }}}{V_{c}} x_{c}-\frac{Q_{\text {liv, art }}}{V_{\text {liv }}} x_{\text {liv }}-\frac{C L_{1}+C L_{2} I}{V_{\text {liv }}} x_{\text {liv }}
\end{aligned}
$$

$x_{c}$ and $x_{\text {liv }}$ are the drug amounts in the central and liver compartment, respectively. $V_{c}$ and $V_{\text {liv }}$ are the central and liver compartment volumes and $Q_{\text {liv, art }}$ is the arterial liver blood flow. The value of $V_{c}$ was taken equal to the median of drug distribution volumes in [17] minus $V_{\text {liv }} . C L_{1}$ and $C L_{2}$ are the clearances of enzyme 1 and enzyme 2, respectively, and $I$ is an inhibition constant. The clearance expression is given in (2).

$$
C L=C L_{\text {int }} \cdot[E]_{\text {mic }} \cdot M P P G L \cdot M_{\text {liv }}
$$

$C L_{\text {int }}$ is the intrinsic clearance, $[E]_{m i c}$ is the enzymatic concentration per $m g$ of microsomal proteins, MPPGL is the $m g$ of microsomal protein per $g$ of liver and $M_{l i v}$ the liver mass in $g$ [6]. As an exercise, the distributions of microsomal concentrations of both $E_{1}$ and $E_{2}$ were taken to equal the one of CYP3A4. We choose to set the intrinsic clearance and the distributions of $E_{1}$ and $E_{2}$ to equal values. This was done to give equal importance to the two enzymes on the drug metabolism (for an average individual) and thus highlight the impact of correlation effect where present. All the model parameters were considered fixed to their mean value, shown in Table 1, except $C L_{\text {int }}, I$ and the concentrations of the two enzymes. As for CYP3A4, both concentrations of enzyme 1 and 2 were assumed to be log-normally distributed [18] as shown in (3).

$$
\left[\begin{array}{l}
\log \left(\left[E_{1}\right]\right) \\
\log \left(\left[E_{2}\right]\right)
\end{array}\right] \sim \log N\left(\left[\begin{array}{l}
{\left[l \mu_{1}\right]} \\
{\left[l \mu_{2}\right]}
\end{array}\right],\left[\begin{array}{cc}
\sigma_{1}^{2} & \rho \sigma_{1} \sigma_{2} \\
\rho \sigma_{1} \sigma_{2} & \sigma_{2}^{2}
\end{array}\right]\right)
$$

where $l \mu_{i}$ and $\sigma_{i}$ are the mean and standard deviation of the natural logarithm of the concentration of enzyme $i$. Both presence and absence of correlation between the two enzymes were considered. In particular, when the correlation is present it was assumed that $\rho=0.7$, close to the physiological 
correlation between the logarithms of CYP3A4 and CYP2C8 microsomal concentrations ${ }^{1} . C L_{\text {int }}$ was considered variable within the ranges of 0.005 to $2949 \mu \mathrm{L} / \mathrm{min} / \mathrm{mg}$ microsomal protein as reported in [19]. Given that in [19] the values of $C L_{\text {int }}$ are expressed in $\mu L / m i n / m g$ microsomal protein, in order to express the clearance in $\mu L / \mathrm{min} / \mathrm{pmol} C Y P$, the original values were divided by the mean concentration of CYP3A4 per $m g$ of microsomal protein. Values of $I$ were considered between 0 and 2, which corresponds to complete inhibition and two-fold induction of the $\mathrm{E}_{2}$, respectively. A total of 5,000 samples were extracted from the enzyme concentration distribution in both cases of presence and absence of correlation. The considered timespan ranged from 0 (time of dose administration) to $100 \mathrm{~h}$. For the given values of $C L_{\text {int }}$ and $I$, the AUC from 0 to $100 \mathrm{~h}$ of the central compartment following an IV bolus of $1 \mathrm{mg}$ was calculated for all the paired enzyme concentration samples. Thus, for each $C L_{\text {int }}$ and $I$ combination, two AUC distributions were obtained: one in presence and the other one in absence of correlation between the enzyme concentrations. The index $R_{P}$ was defined as in equation (4), with $A U C_{P, \text { corr }}$ and $A U C_{P, \text { not corr }}$ given percentiles relative to the correlated and not correlated distribution of the AUC, respectively.

$$
R_{P}=\frac{A U C_{P, \text { corr }}-A U C_{P, \text { not corr }}}{A U C_{P, \text { not corr }}}
$$

$R_{P}$ represents the increase in the $P^{\text {th }}$ AUC percentile, $A U C_{P}$, due to the presence of correlation, relative to absence of any correlation. An $R_{P}>0$ for the upper limit of the $95 \%$ confidence interval, means that this limit is increased to $\left(R_{p} \cdot 100\right) \%$ due to the presence of correlation. Instead, an $R_{p}<$ 0 for the lower limit of the $95 \%$ confidence interval, means that this limit is reduced to $\left(R_{p} \cdot 100\right) \%$. The reasoning could be easily extended for $R_{p}<0$ for the upper limit and $R_{p}>0$ for the lower limit. $R_{P}$ was calculated for the $5^{\text {th }}, 50^{\text {th }}$ and $95^{\text {th }}$ percentiles. Given that $R_{P}$ depends on $C L_{\text {int }}$ and $I$, its value was calculated for a grid of values of these two parameters. This grid was obtained by the combination of 20 values for both $C L_{i n t}$ and $I$, equally spaced between the ranges given before. Given that $C L_{\text {int }}$ spans in several orders of magnitude, a logarithmic spacing with lower and upper bounds set as the logarithms of minimum and maximum value in [19], respectively, was used for values of $C L_{\text {int }}$. To establish the values of $I$, a linear spacing with a lower bound equal to 0 and an upper bound equal to 2 was used. Finally, for each value of $C L_{\text {int }}$, the ratio $\left(R_{\text {inh }}\right)$ between central compartment AUC when $I=0$ (complete inhibition of $E_{2}$ ) and when $I=1$ (absence of inhibition), was calculated for both the presence and absence of correlation.

\footnotetext{
${ }^{1}$ Data on CYP3A4 and CYP2C8 paired microsomal concentration on 23 Caucasian subjects were internally available [9]. The Pearson linear coefficient was calculated by using the MATLAB function corr, on the logarithms of the CYPs concentrations, resulting in $\rho=0.7436$.
} 


\section{CYP3A4 in gut wall and in liver}

A semi-physiological model was set up to describe the absorption and first pass effect for a generic drug. The model, shown in Figure 1b, is composed of four compartments, representing intestinal lumen, the enterocytes, the liver and the cumulative amount of drug reaching the systemic circulation. Model equations are shown in (5).

$$
\begin{aligned}
\frac{d x_{\text {lum }}}{d t} & =-\left(k_{a}+k_{t}\right) x_{\text {lum }} \\
\frac{d x_{\text {ent }}}{d t} & =k_{a} x_{\text {lum }}-\left(\frac{C L_{\text {ent }} I}{V_{\text {ent }}}+\frac{Q_{\text {ent }}}{V_{\text {ent }}}\right) x_{\text {ent }} \\
\frac{d x_{\text {liv }}}{d t} & =\frac{Q_{\text {ent }}}{V_{\text {ent }}} x_{\text {ent }}-\left(\frac{C L_{\text {liv }} I}{V_{\text {liv }}}+\frac{Q_{\text {liv }}}{V_{\text {liv }}}\right) x_{\text {liv }} \\
\frac{d x_{\text {sys }}}{d t} & =\frac{Q_{\text {liv,ven }}}{V_{\text {liv }}} x_{\text {liv }}
\end{aligned}
$$

$x_{l u m}, x_{e n t}, x_{l i v}$ and $x_{s y s}$ represent drug amount in gastrointestinal lumen, enterocytes, liver and cumulative amount that reaches the systemic circulation, respectively. $k_{a}=2 \cdot P_{e f f} / r_{i}$ is the absorption constant, with $r_{i}=1.75 \mathrm{~cm}$ the mean intestine lumen radius and $P_{e f f}$ the effective permeability [20]. $P_{\text {eff }}$ was taken to equal to the maximum value in [20] $\left(8.70 \cdot 10^{-4} \mathrm{~cm} / \mathrm{s}\right)$ to allow maximal drug absorption. $k_{t}$ is the time constant relative to small intestine transit. $V_{\text {ent }}$ and $V_{\text {liv }}$ are the enterocyte and liver volumes and $Q_{e n t}$ and $Q_{l i v, v e n}$ are the enterocyte and venous liver blood flows, respectively. $C L_{e n t}$ and $C L_{l i v}$ are the clearances due to CYP3A4 activity in the gut wall (equation (6)) and the liver (equation (2)) and $I$ is the inhibition constant.

$$
C L_{\text {ent }}=C L_{\text {int }, 3 A 4} C Y P 3 A 4_{\text {ent }}
$$

$C L_{\text {int } 3 A 4}$ is the intrinsic clearance and $C Y P 3 A 4_{\text {ent }}$ is the CYP3A4 amount in enterocytes. The analytical expression for the bioavailability $\left(F_{\text {oral }}\right)$ was derived and is shown in (7), where $D_{0}$ is the drug dose. Derivation is shown in appendix A.

$$
F_{\text {oral }}=\lim _{t \rightarrow+\infty} \frac{x_{\text {sys }}}{D_{0}}=\frac{k_{a} \cdot\left(Q_{\text {ent }} / V_{\text {ent }}\right) \cdot\left(Q_{\text {liv, ven }} / V_{\text {liv }}\right)}{\left(k_{a}+k_{t}\right)\left(\frac{Q_{\text {ent }}}{V_{\text {ent }}}+\frac{C L_{\text {ent }}}{V_{\text {ent }}} \cdot I\right)\left(\frac{Q_{\text {liv }, \text { ven }}}{V_{\text {liv }}}+\frac{C L_{\text {liv }}}{V_{\text {liv }}} \cdot I\right)}
$$

All the parameters were considered fixed, except $C L_{i n t, 3 A 4}, I, C Y P 3 A 4_{\text {ent }}$ and the microsomal CYP3A4 concentration $[C Y P 3 A 4]_{m i c} . C L_{i n t, 3 A 4}$ and $I$ were considered as in the section titled Two enzymes in the liver. Both $C Y P 3 A 4_{\text {ent }}$ and $[C Y P 3 A 4]_{m i c}$ were considered log-normally distributed $[18,21]$. As an exercise, both presence and absence of correlation between CYP3A4 amount in the 
enterocytes and CYP3A4 concentration in liver microsomes, were considered. In the former case, the correlation coefficient $\rho$ was set equal to 0.7 .

As in the previous section, 5,000 samples were extracted from the joint distribution of CYP3A4 in gut wall and liver in the case of presence and absence of correlation. Then, the index $R_{P}$ was calculated for $F_{\text {oral }}$, for each combination of $C L_{\text {int }}$ and $I . R_{P}$ was calculated for the $5^{\text {th }}, 50^{\text {th }}$ and $95^{\text {th }}$ percentiles. Finally, for each value of $C L_{i n t}$ the ratio $\left(R_{i n h}\right)$ was calculated between bioavailability when $I=0$ (complete inhibition of both CYP3A4 in gut wall and liver) and when $I=1$ (absence of inhibition). The analytical expression of $R_{i n h}$ is reported in (8).

$$
R_{\text {inh }}=\frac{\left(\frac{Q_{\text {ent }}}{V_{\text {ent }}}+\frac{C L_{\text {ent }}}{V_{\text {ent }}}\right)\left(\frac{Q_{\text {liv,ven }}}{V_{\text {liv }}}+\frac{C L_{\text {liv }}}{V_{\text {liv }}}\right)}{\frac{Q_{\text {ent }}}{V_{\text {ent }}} \cdot \frac{Q_{\text {liv,ven }}}{V_{\text {liv }}}}
$$

\section{OATP1B1 and CYP3A4 in liver}

A semi-physiological model was developed to describe IV administration of $1 \mathrm{mg}$ of a generic substrate of CYP3A4 and OATP1B1. The model, represented in Figure 1c, is composed of one central compartment and two compartments representing the extracellular and intracellular space of the liver. Model equations are shown in (9).

$$
\begin{aligned}
\frac{d x_{c}}{d t} & =\frac{Q_{l i v, \text { art }}}{V_{l i v, \text { ext }}} x_{l i v, \text { ext }}-\frac{Q_{\text {liv, art }}}{V_{c}} x_{c} \\
\frac{d x_{l i v, \text { ext }}}{d t} & =\frac{Q_{l i v, \text { art }}}{V_{c}} x_{c}-\left(\frac{Q_{l i v, \text { art }}}{V_{l i v, \text { ext }}}+\frac{C L_{O A T P}}{V_{l i v, \text { ext }}}+\frac{C L_{P S}}{V_{l i v, \text { ext }}}\right) x_{l i v, \text { ext }}+\frac{C L_{P S}}{V_{l i v, \text { int }}} x_{l i v, \text { int }} \\
\frac{d x_{l i v, \text { int }}}{d t} & =\left(\frac{C L_{\text {OATP }}}{V_{l i v, \text { ext }}}+\frac{C L_{P S}}{V_{l i v, \text { ext }}}\right) x_{l i v, \text { ext }}-\left(\frac{C L_{C Y P}}{V_{l i v, \text { int }}}+\frac{C L_{P S}}{V_{l i v, \text { int }}}\right) x_{l i v, \text { int }}
\end{aligned}
$$

$x_{c}, x_{\text {liv,ext }}$ and $x_{\text {liv,int }}$ are drug amount in central, extracellular and intracellular liver compartments, respectively. $V_{c}, V_{\text {liv,ext }}$ and $V_{\text {liv,int }}$ are central, extracellular and intracellular liver volumes, respectively. $Q_{\text {liv, art }}$ is the liver arterial blood flow. $C L_{C Y P}$ represents the CYP3A4 mediated clearance, as shown in the previous sections. $C L_{O A T P}$ is the active transport clearance from the extracellular to the intracellular liver compartment and $C L_{P S}$ is the passive clearance across the hepatocytes' plasmatic membrane. $C L_{O A T P}$ is defined in the following equation (10).

$$
C L_{O A T P}=C L_{\text {int }, \text { OATP }} \cdot[O A T P 1 B 1]_{\text {cells }} \cdot H P G L \cdot M_{\text {liv }}
$$

$C L_{\text {int,OATP }}$ is the intrinsic clearance, $[O A T P 1 B 1]_{\text {cells }}$ is the OATP1B1 concentration per $10^{6}$ hepatocytes, HPGL the hepatocellularity per gram of liver and $M_{l i v}$ the liver mass in $g$. 
All the model parameters were fixed, except $C L_{\text {int }, 3 A 4}, C L_{\text {int }, O A T P},[O A T P 1 B 1]_{\text {cells }}$ and $[C Y P 3 A 4]_{m i c}$. Both $[O A T P 1 B 1]_{\text {cells }}$ and $[C Y P 3 A 4]_{m i c}$ were considered log-normally distributed and, as an exercise, both the presence and absence of correlation between their expression were considered. In the former case the correlation coefficient $\rho$ was set equal to 0.7 .

The ranges of $C L_{O A T P}$ were taken from the uptake parameters in human hepatocytes [22]. With the hypothesis that active transport was mainly due to OATP1B1 activity, clearance values in [22] were converted from $\mu L / \mathrm{min} / 10^{6}$ hepatocytes to $\mu L / \mathrm{min} / \mathrm{pmol} O A T P 1 B 1$, by dividing them by the mean OATP1B1 concentration per $10^{6}$ hepatocytes. $C L_{P S}$ was defined as $21.65 \%$ of the total transport clearance at a mean OATP1B1 concentration ${ }^{2}$.

As done in the previous sections, 5,000 samples from $[O A T P 1 B 1]_{\text {cells }}$ and $[C Y P 3 A 4]_{m i c}$ distributions were extracted both in presence and absence of correlation. Then, the index $R_{P}$ was calculated for the AUC in the central compartment, for each combination of $C L_{\text {int,OATP }}$ and $C L_{\text {int }, 3 A 4} \cdot R_{P}$ was calculated for the $5^{\text {th }}, 50^{\text {th }}$ and $95^{\text {th }}$ percentiles. The time span that was considered ranged from 0 (dose administration) to $100 h$.

\section{GSA in case of correlation: repaglinide example}

\section{Variance based GSA}

Variance based GSA quantifies the contribution of the uncertainty of each model parameter $\left(P_{i}, i=\right.$ $1 \ldots k)$, considered in its whole range of variation, with respect to the variation in model output $Y$ (e.g., central compartment AUC). Two sensitivity indices, called main effect $\left(S_{i}\right)$ and total effect $\left(S_{T, i}\right)$, are derived for each parameter $P_{i}$ from the decomposition of the output variance, $V(Y)$. $S_{i}$ is the part of the variance explained by the variation of each parameter $P_{i}$ taken singularly and $S_{T, i}$ is $S_{i}$ plus the interaction effects involving $P_{i}$. Both the indices are in the range 0-1 and $S_{T, i}$ is always greater or equal than $S_{i}$. The higher $S_{i}$ or $S_{T, i}$ are, the more the $i^{\text {th }}$ parameter $P_{i}$ explains $V(Y)$ and, consequently, the more important it is. Conversely, a parameter that has a low $S_{T, i}$ is considered less important [13-15].

A program to perform variance based GSA was developed in MATLAB. Following suitable rules [13], the program extracted samples from a $k$-dimensional unit hypercube, with $k$ equal to the number of parameters, by using a Latin hypercube sampling method (lhsdesign function in

\footnotetext{
${ }^{2}$ In [22] the percentages of active clearance with respect to the total transport clearance are reported. The fixed percentage of passive clearance was calculated as 1 minus the median of the active clearance percentages reported in the article. Total clearance was obtained dividing the active clearance for the fraction of active clearance.
} 
MATLAB). Then, the inverse cumulative distribution function (icdf function in MATLAB) was used to convert each sample to the parameter distribution. Finally, the model was evaluated for each of the extracted values and the outputs were calculated. All the outputs were used to compute the sensitivity indices $[13,14]$.

\section{Application on repaglinide reduced PBPK}

A semi-physiological model, represented in Figure 1d, was developed to describe repaglinide PK after an IV infusion of $2 \mathrm{mg}$ over 15 minutes. The model is composed of one central compartment and two compartments representing the extracellular and intracellular space of the liver. Active transport due to OATP1B1 and metabolism due to CYP3A4 and CYP2C8 are included. Model equations are shown in (11).

$$
\begin{aligned}
& \frac{d x_{c}}{d t}=\frac{Q_{\text {liv,art }}}{V_{\text {liv,ext }}} x_{\text {liv,ext }}-\frac{Q_{\text {liv, art }}}{V_{c}} x_{c} \\
& \frac{d x_{\text {liv,ext }}}{d t}=\frac{Q_{\text {liv,art }}}{V_{c}} x_{c}-\left(\frac{Q_{\text {liv, art }}}{V_{\text {liv,ext }}}+\frac{C L_{\text {OATP }} \cdot f u_{t}}{V_{\text {liv,ext }}}+\frac{C L_{P S} \cdot f u_{t}}{V_{\text {liv,ext }}}\right) x_{\text {liv,ext }} \\
& +\frac{C L_{P S} \cdot f u_{t}}{V_{l i v, i n t}} x_{\text {liv,int }} \\
& \frac{d x_{\text {liv,int }}}{d t}=\left(\frac{C L_{O A T P} \cdot f u_{t}}{V_{l i v, \text { ext }}}+\frac{C L_{P S} \cdot f u_{t}}{V_{l i v, \text { ext }}}\right) x_{l i v, \text { ext }} \\
& -\left(m e t_{3 A 4}+m t_{2 C 8}+\frac{C L_{P S} \cdot f u_{t}}{V_{l i v, i n t}}\right) x_{l i v, i n t} \\
& \operatorname{met}_{3 A 4}=\frac{V_{\max , 3 A 4} C Y P 3 A 4_{\text {liv }}}{K_{M, 3 A 4}+x_{\text {liv,int }} \cdot f u_{t} / V_{\text {liv,int }}} \cdot \frac{f u_{t}}{V_{\text {liv, int }}} \\
& \text { met }_{2 C 8}=\frac{V_{\max , 2 C 8} C Y P 2 C 8_{\text {liv }}}{K_{M, 2 C 8}+x_{\text {liv,int }} \cdot f u_{t} / V_{\text {liv,int }}} \cdot \frac{f u_{t}}{V_{\text {liv,int }}}
\end{aligned}
$$

$x_{c}, x_{l i v, e x t}$ and $x_{\text {liv,int }}$ are the drug amounts in central compartment, extracellular and intracellular liver compartments, respectively. $V_{c}, V_{\text {liv,ext }}$ and $V_{\text {liv,int }}$ are the central compartment, extracellular and intracellular liver volumes, respectively. $Q_{l i v, a r t}$ is the liver arterial blood flow and $f u_{t}$ is the fraction unbound drug in the liver tissue $[23,24] . C L_{O A T P}$ is the transporter clearance, defined as in (10), and $C L_{P S}$ is the passive clearance. $V_{\max , 3 A 4}, K_{M, 3 A 4}, V_{\max , 2 C 8}$ and $K_{M, 2 C 8}$ are the MichaelisMenten parameters of CYP3A4 and CYP2C8 catalysed reactions, respectively [25]. $V_{\text {max }}$ values in [25] were converted from $\mathrm{pmol} / \mathrm{min} / \mathrm{mg}$ microsomal protein to $\mathrm{pmol} / \mathrm{min} / \mathrm{pmol} \mathrm{CYP}$ by dividing them by the mean microsomal CYP concentration. $C Y P 3 A 4_{\text {liv }}$ and $C Y P 2 C 8_{\text {liv }}$ are the amounts of CYP3A4 and CYP2C8 in the liver. Enzyme amounts are calculated as the enzymatic 
concentration per $m g$ of protein, times MPPGL, times liver mass in grams [6]. All the parameters were considered fixed, except OATP1B1, CYP3A4 and CYP2C8 abundances which were considered log-normally distributed.

A variance based GSA was performed on the predicted central compartment AUC, considering different levels of correlation between CYP3A4 and CYP2C8 microsomal concentrations. The joint distribution of the two CYPs' microsomal concentration is shown in equation (3). We considered different linear correlation coefficients $(\rho)$ between the natural logarithm of the two cytochromes' concentrations: 0 (absence of correlation), $0.1,0.3,0.5,0.7,0.9$ and a physiological $\rho$ equal to 0.7436 [9]. OATP1B1 abundance was considered to be independent from CYP3A4 and CYP2C8 since there information on correlations between transporters and enzymes are currently sparse and starting to emerge [26].

To express the correlation between CYP3A4 and CYP2C8 a linear regression with the addition of a noise term was used, as suggested by [13]. For each of the correlation coefficient, 1,000 samples were extracted from the joint probability distribution of the natural logarithms of CYP3A4 and CYP2C8 concentrations. On these samples, parameters of a linear regression $\left(\beta_{0}\right.$ and $\left.\beta_{1}\right)$ were identified considering CYP2C8 concentrations as a function of CYP3A4 concentration, a constant standard deviation for the residual error.

CYP2C8 concentrations were then expressed as the values predicted by using the regression with the addition of a noise term $\varepsilon$, as reported in (12).

$$
\log \left([C Y P 2 C 8]_{m i c}\right)=\beta_{0}+\beta_{1} \log \left([C Y P 3 A 4]_{m i c}\right)+\varepsilon
$$

$\varepsilon$ was considered normally distributed with a mean equal to 0 and variance equal to the one estimated from the residuals of the linear regression.

Then, for each correlation level, a variance based GSA was performed. $n$ samples extracted from the $k$-dimensional unit hypercube, with $k=3$ (number of parameters), were manipulated to obtain the OATP1B1 and CYP3A4 concentration distributions and the distribution of $\varepsilon . n$ was set equal to 7,000 , corresponding to $n(k+2)$ model evaluations. The analysis was repeated five times to assess the variability of the sensitivity indices estimation. In conclusion, for each correlation level we calculated the main and the total effect for all the variable model parameters (i.e., CYP3A4, CYP2C8 and OATP1B1 concentrations).

Finally, the same analysis was performed again, considering CYP3A4 expressed as a function of CYP2C8, with the purpose to assess the impact of the arbitrary decision of what variable is the independent one in the linear regression model. 
2

\section{Results}

\section{Two enzymes in the liver}

For the model represented in Figure 1a and described in (1), the distribution of central compartment AUC was simulated for each combination of $C L_{\text {int }}$ and $I$, both in case of presence and absence of correlation between the liver expression of the two enzymes metabolising the drug. Then, for each of these AUC distribution pairs, the index $R_{P}$, in (4), was calculated for the $5^{\text {th }}, 50^{\text {th }}$ and $95^{\text {th }}$ percentiles. Results are shown in Figure 2.

Due to the presence of correlation between $E_{1}$ and $E_{2}$, the $5^{\text {th }}$ percentile of the central compartment AUC is reduced by more than $5 \%$ and the $95^{\text {th }}$ percentile increases by more than $15 \%$, while the median remains almost stable. In the presence of correlation, when $E_{1}$ is highly expressed, $E_{2}$ is likely to be highly expressed as well. Instead, in case of absence of correlation, if $E_{1}$ is highly expressed then $E_{2}$ is equally likely to have any expression level according to its distribution. Therefore, in presence of correlation, the metabolism is likely to be higher, and thus the AUC is lower. For the same reason, in case of low expression of one of the two enzymes, the metabolism is likely to be lower, and so the AUC is higher if the enzymes are correlated, as compared to the case of uncorrelated expressions. For central values of $C L_{\text {int }}$ a higher correlation effect can be observed while a lower effect can be observed for extreme $C L_{\text {int }}$ values. For higher $C L_{\text {int }}$ values, this is probably a consequence of the metabolism becoming flow-limited and therefore less dependent on enzymatic abundances. For lower $C L_{\text {int }}$ values the clearance is so low that even inhibiting one enzyme does not change the overall absolute metabolic clearance.

For each value of $C L_{\text {int }}$, the ratio $\left(R_{\text {inh }}\right)$ between the central compartment AUC when $I=0$ and when $I=1$ was calculated in case of presence $\left(R_{\text {inh,corr }}\right)$ and absence $\left(R_{\text {inh,not corr }}\right)$ of correlation. Then, the ratio $R_{\text {inh,corr }} / R_{\text {inh,not corr }}$ was computed and the results are shown in Figure 3 . When the correlation between enzymatic expression is present, the distribution of $R_{\text {inh }}$ is narrower in comparison to the absence of correlation. This effect is more apparent for central $C L_{\text {int }}$ values and it is weaker for extreme $C L_{i n t}$ values. In presence of correlation, when $E_{1}$ has high expression, $E_{2}$ is likely to have high expression and so when $E_{2}$ is completely inhibited, the capacity for drug metabolism via $E_{1}$ is still high. In this case, the change in AUC values would be limited compared to the case of absence of correlation, in which most of the metabolism could be due to the activity of one enzyme alone. Instead, if $E_{1}$ has low expression, $E_{2}$ is likely to have low expression, thus the metabolism would still be low in case of complete inhibition of $E_{2}$, therefore the AUC values would still be high. In the case of absence of correlation, the complete inhibition of one enzyme could 
dramatically change the AUC values. For these reasons, the distribution of $R_{\text {inh }}$ is narrower in the presence of correlation. The correlation effect is higher for central $C L_{\text {int }}$ values and lower for extreme $C L_{i n t}$ values, probably for the same reasons as it is for $R_{P}$ : for higher $C L_{\text {int }}$ values the metabolism becomes flow-limited and so less dependent on enzymatic expression, while for lower $C L_{\text {int }}$ values the clearance is so low that even inhibiting one enzyme does not change the overall absolute metabolic clearance.

\section{CYP3A4 in gut wall and in liver}

For the model represented in Figure $1 \mathrm{~b}$ and described by equation system (5), the $F_{\text {oral }}$ distribution was calculated for each combination of $C L_{i n t}$ and $I$, both in the case of presence and absence of correlation between CYP3A4 expression in the gut wall and liver. Then, for each of these AUC distribution pairs, the index $R_{P}$ was calculated for the $5^{\text {th }}, 50^{\text {th }}$ and $90^{\text {th }}$ percentiles. Results are shown in Figure 4.

In presence of the correlation, the $5^{\text {th }} F_{\text {oral }}$ percentile decreases of more than $20 \%$ and the $95^{\text {th }}$ percentile increases of more than $35 \%$, while the median remains stable. This effect mainly occurs for high $C L_{\text {int }}$ values. In the case of correlation, for high liver CYP3A4 expression, it is likely to be high also the gut wall CYP3A4 expression. Instead, in absence of correlation, for high values of liver CYP3A4 expression, the gut wall expression could equally likely be any value, according to its distribution. In such cases, when the correlation is present, the metabolism is likely to be higher, thus the $F_{\text {oral }}$ lower. For the same reasons, in case of low CYP3A4 expression in one of the two sites, the metabolism is likely to be lower, and so the $F_{\text {oral }}$ to be higher, if the enzymes are correlated, with respect to the case of absence of correlation. The correlation effect could mainly be observed for high $C L_{i n t}$ values, as compared to mean or low $C L_{i n t}$ values, in which little or no effect is observed. Therefore, the effect of the correlation could only be seen for low values of oral bioavailability. In Figure 5, for central or lower $C L_{\text {int }}$ values, the fraction of the drug metabolised in the liver is much higher with respect to the one metabolised in the gut wall. The two fractions start to be comparable only for high $C L_{\text {int }}$ levels, and so this is probably why the effect of the correlation is stronger in these cases.

For each value of $C L_{\text {int }}$, the ratio $\left(R_{\text {inh }}\right)$ of $F_{\text {oral }}$ in case of complete inhibition of CYP3A4 in both gut wall and liver $(I=0)$ and in case of absence of inhibition $(I=1)$ was calculated. Results are reported in Figure 6. It can be seen that the distribution of the ratio is slightly wider in the case of presence of correlation as compared to no correlation. It is possible to explain this behaviour by looking at the $R_{\text {inh }}$ analytical expression in equation (8). In fact, if the expressions of CYP3A4 in gut wall and liver are correlated, it is more likely that low values of clearance in the gut wall 
correspond to low values of clearance in the liver, leading to higher $F_{\text {oral }}$ in comparison to the case of absence of correlation. Similarly, in the presence of correlation, high values of clearance in the gut wall are likely to correspond to high values of clearance in the liver, leading to a lower $F_{\text {oral }}$. In case of complete inhibition of CYP3A4 metabolism in only one of the two sites, for example the gut wall (as is the case for grapefruit juice interaction studies [27]), the ratio of $F_{\text {oral }}$ in the inhibited state over $F_{\text {oral }}$ in absence of inhibition, is equal to $\left(\frac{Q_{e n t}}{V_{\text {ent }}}+\frac{C L_{\text {ent }}}{V e n t} I\right) /\left(\frac{Q_{\text {ent }}}{V_{\text {ent }}}+\frac{C L_{\text {ent }}}{V e n t}\right)$. Thus, in these cases the ratio does not depend on the correlation between CYP3A4 in the gut wall and liver.

\section{OATP1B1 and CYP3A4 in liver}

For the model represented in Figure 1c and described in (9), the distribution of central compartment AUC was simulated for each combination of $C L_{\text {int,CYP }}$ and $C L_{\text {int,OATP }}$, in both the cases of presence and absence of correlation between the liver expression of the two enzymes metabolising the drug. Then, for each of these AUC distribution pairs, the index $R_{P}$ was calculated for $5^{\text {th }}, 50^{\text {th }}$ and $95^{\text {th }}$ percentiles. Results are shown in Figure 7.

Due to the presence of correlation between OATP1B1 and CYP3A4, the central compartment AUC $5^{\text {th }}$ percentile is reduced by more than $20 \%$, the $95^{\text {th }}$ percentile increases by more than $25 \%$ and the median remains stable. In case of correlation, high OATP1B1 concentrations are likely to correspond to high CYP3A4 concentrations. Therefore, the drug is quickly transported into the intracellular liver compartment and is then rapidly metabolised. This leads to lower central compartment AUC values compared to the absence of correlation, where high OATP1B1 concentrations could equally likely correspond to high or low CYP3A4 concentrations. Similarly, in the case of correlation low OATP1B1 concentrations are likely to correspond to low CYP3A4 concentrations and therefore leads to higher central compartment AUC values. 


\section{GSA on repaglinide reduced PBPK}

Variance based global sensitivity analysis was performed on central compartment AUC, as predicted using the reduced repaglinide PBPK model represented in Figure 1d and described by equation system (11). The main and total effects were calculated for CYP3A4, CYP2C8 and OATP1B1 concentrations. The correlation between the two cytochromes microsomal concentrations was modelled trough a linear regression with CYP3A4 and CYP2C8 being the independent and dependent variable, respectively. Results are shown in Figure 8 and 9. In case of absence of correlation $(\rho=0)$, the parameter that mostly explains the central compartment AUC variance is the OATP1B1 concentration, followed by CYP2C8 and CYP3A4 concentrations, with total effects equal to $0.5456,0.434$ and 0.1617 , respectively. Despite the lower mean microsomal concentration and lower $V_{\max }$ in the case of repaglinide metabolism, variability in the abundance of CYP2C8 is more important than variability in CYP3A4 when it comes to explaining the variance in AUC. This could be explained by the higher variability of microsomal CYP2C8 and by the lower value of $K_{M}$ for repaglinide, as compared to that of CYP3A4. Moving towards higher correlation coefficients, the importance of OATP1B1 and CYP2C8 concentrations is reduced and the importance of CYP3A4 concentrations is increased. In the case of physiological correlation ( $\rho=0.7436)$, the total effects of OATP1B1, CYP2C8 and CYP3A4 concentrations are equal to $0.4499,0.122$ and 0.5174 , respectively. The increased importance of CYP3A4 and reduced importance of CYP2C8 as correlation increases are probably mainly a consequence of CYP2C8 being dependent on CYP3A4. This because CYP2C8 concentrations are derived through a linear regression where CYP3A4 is the independent variable. Moreover, the variability of $\varepsilon$, the residual variability or error, decreases as $\rho$ increases. In fact, the variance of $\varepsilon$ is reduced from 1.8629 when $\rho=0$, to 0.8329 when $\rho=0.7436$.

Instead, in equation system (11), the parameters related with OATP1B1 concentration distribution do not change through different correlation levels between the two CYPs. So, the reduction of OATP1B1 main and total effect when $\rho$ increases, is explained by the increase of the level of correlation between CYP3A4 and CYP2C8. Thus, the more CYP3A4 and CYP2C8 are correlated, the less OATP1B1 is influent on central compartment AUC variance.

The results of the analysis performed considering CYP3A4 as a function of CYP2C8 are shown in Figure 10. In summary, the observations are: 1) when $\rho$ is equal to 0 the main and total effect of all the tree parameters are the same to the ones shown in Figure 8; 2) main and total effect of OATP1B1 does not change across the different correlation levels with respect to the ones shown in Figure 8. The differences seen in the results of the analysis shown in Figure 8 are that in this case CYP2C8 main and total effect increase and CYP3A4 main and total effect are reduced, as $\rho$ 
1 increases. This because, similarly to the results explained above, CYP3A4 concentrations depend ${ }_{2}^{1} 2$ on CYP2C 8 concentrations.

3

43

5

6

7

8

9

10

11

12

13

14

15

16

17

18

19

20

21

22

23

24

25

26

27

28

29

30

31

32

33

34

35

36

37

38

39

40

41

42

43

44

45

46

47

48

49

50

51

52

53

54

55

56

57

58

59

60

61 


\section{Discussion}

The aims of this work were, first of all, to perform a simulation analysis to assess the effect of the correlation between enzymatic expressions at different sites in the body on the PK of different types of drugs and second, to understand how the correlation between enzymatic abundances impacts the results of global sensitivity analysis.

In this context, three semi-physiological models were considered to describe the PK of generic drugs metabolised by two enzymes with correlated expressions, in order to analyse the following cases: 1) impact of the correlation between the expression of two enzymes present in the liver on the plasma AUC of drugs that are metabolized by both these enzymes; 2) impact of the correlation between gut wall and liver CYP3A4 expression levels on the bioavailability of CYP3A4 metabolised drugs; 3) impact of the correlation of OATP1B1 and CYP3A4 expressed in the liver on the plasma AUC of drugs that are substrates of both proteins.

Concerning the first case, the correlation acts to enlarge the plasma AUC distribution $\left(R_{P}<-0.05\right.$ for the $5^{\text {th }}$ percentile, $R_{P}>0.1$ for the $95^{\text {th }}$ percentile) and results in a more narrow distribution of the ratio between plasma AUC in presence and in absence of inhibition, especially for mean values of $C L_{\text {int }}$ (Figures 2 and 3). These results are in accordance with the observations reported in [8], in fact in that study it was shown that a PBPK model ignoring correlation between two drugmetabolising enzymes may overestimate the effect of the drug-drug interaction (DDI) when one of the two enzymes is inhibited. Concerning the second case, the effect on the bioavailability seems to be relevant $\left(R_{P}<-0.2\right.$ for the $5^{\text {th }}$ percentile, $R_{P}>0.2$ for the $95^{\text {th }}$ percentile) only for high levels of intrinsic clearance. However, it must be considered that in this analysis we did not included the dissolution process and we considered high absorption. So, the results are limited to the above situation. Finally, concerning the third case, the correlation shows its effect on plasma AUC especially for mean levels of $C L_{\text {int }}\left(R_{P}<-0.2\right.$ for the $5^{\text {th }}$ percentile, $R_{P}>0.2$ for the $95^{\text {th }}$ percentile). The correlation between OATP1B1 and CYP3A4 expressions may be considered a theoretical exercise alone given the fact that, to our knowledge, there are no data available to support (or reject) this hypothesis.

Further, we have to consider the fact that in this analysis we used simple semi-physiological models, with a limited number of compartments and limited sources of variability (practically exclusively limited to the parameters that are considered correlated), and not complex whole body PBPK models (such as: Simcyp Simulator, GastroPlus and more). This was done to highlight the effect of the correlation, if present, and to allow an easier interpretation of the results. The problem of using a whole body PBPK is that there are too many variables to control, consequently, the 
parameters space would become too large to analyse and so, one is forced to reduce it considering, for example, a specific case drug (e.g., repaglinide [8]). With simple compartmental models the parameters space is reduced, and it becomes possible to investigate more generally in what parameter space interaction effects occur and their extent in function of set of parameters (e.g., the intrinsic clearance). This would not directly correspond to a specific drug or class of drugs. However, our study could be a useful guide to indicate in what situations the correlation may have a potential effect.

The results of this analysis show the necessity of considering the correlation between enzymatic expressions in physiological model when confidence in biological evidence for such correlations is high. Otherwise, there is a risk of underestimating the population variability or overestimate the effect of DDI (though this is shown for direct correlations of enzymes and the reverse could be true if the enzyme abundances were inversely related). To remain true to the knowledge of the system, PBPK platforms should not ignore known correlations of any of the model parameters. However, one has to consider that in a whole body PBPK model (unlike the minimal model used in our investigation), it is likely that some of our findings might be mitigated due lack of dominance of parameters that we intentionally selected in this study. Our study considered some conditions (e.g., equal intrinsic clearance between two correlated enzymes) which were in favour of propagating the inter-correlation effect to make the point and these may not be the case at the presence of multiple parameters variabilities and correlations.

This analysis could be also useful for informing experimental design, for instance to assess the impact of hypothetical correlations prior to the generation of the data. For example, in order to asses if a correlation exists between CYP3A4 in gut wall and in liver, an appropriate number of paired samples in the same subjects should be collected. This could be challenging in terms of sample collection and expensive. Knowing that this correlation, even if present, has little or no impact except for high intrinsic clearance drugs, could be useful information when choosing what experiments to prioritise and their design.

Given the recent interest of the EMA in sensitivity analysis [1], we wanted to investigate the impact of the correlation between enzymatic abundances when performing GSA. A variance based GSA was performed on a reduced PBPK model for repaglinide, a substrate drug for CYP3A4 and CYP2C8, these two enzymes have been shown to be correlated in the liver [9]. One initial problem was to find an appropriate methodology to conduct a GSA in the case of correlated parameters. Naïvely, an easy way could be to extract correlated samples from the space of parameters (e.g., enzymatic expression), compute the model outputs (e.g., plasma AUC) for each one of these parameters sets and then perform a GSA using the linear correlation coefficient between the outputs 
and the input parameters. In case of correlated parameters, the results of this analysis could be misleading. For example, let us consider the theoretical case of a model describing the PK of a drug metabolised by CYP3A4 in liver. In a population simulation, plasma AUC would probably be correlated with CYP3A4 liver expression. Considering that the expressions of liver CYP3A4 and CYP2C8 are correlated, the drug plasma AUC would be correlated with CYP2C8 expression. This because the presence of a correlation between the two proteins and not because CYP2C8 plays a role in the metabolism of the drug. So, in these situations, performing a GSA using the correlation coefficient could give misleading results.

In the literature, different methodologies exist to perform GSA in case of correlated parameters, see for example [28-31], but as reported in a recent review: "this issue remains misunderstood" [32]. Therefore, we choose to express the correlation between two parameters using an explicit relationship (in our case linear regression) with a residual error term and then perform a variance based GSA on uncorrelated parameters [13]. Implementing the correlation between parameters can influence the results of the GSA. In fact, in Figures 8 and 9 it can be seen how the OATP1B1 main and total effect change, even if not dramatically, throughout different correlation levels between CYP3A4 and CYP2C8. Nevertheless, with the chosen method for performing the GSA, one should be careful when interpreting the sensitivity indices. In Figure 8 it is possible to observe that the importance of CYP3A4 and CYP2C8 increases and decreases, respectively, as the correlation between the two enzymatic expression increases. This effect is probably mainly due to CYP2C8 being dependent on CYP3A4, because the latter was arbitrarily chosen to be the independent variable in the linear regression and not because the CYP3A4 catalysed reaction acquires more importance. In this analysis we considered the abundances of CYP3A4 and CYP2C8 independent from the one of OATP1B1. If these abundances were correlated, the results would probably be different. It is important to note that the approach used in this paper to treat correlation in GSA is difficult to use when more than two parameters are correlated with each other.

\section{Conclusions}

To our knowledge, this is the first systematic analysis that investigates the impact of correlation between enzymatic abundances on drug clearance and metabolic DDIs with GSA in mind. Implementing the correlation between the enzymatic expression in population physiological models has the potential to impact the results of both predictions and GSA. Ignoring these correlations could lead to the generation of implausible parameter combinations and to incorrect estimation of parameters related to the $\mathrm{PK}$ (e.g., clearance). Thus, it is appropriate to assess experimentally if 
1 these correlations exist, their extent and how they differ with genetics, disease or physiological conditions. The approach presented in this study can be applied to highlight what correlations are of ${ }_{4}^{3} 3$ potential interest and therefore could be useful for informing experimental design. Our work 54 informs the debate that is needed to take place in considering recent data generated by the 75 proteomic analysis and regulatory interest in the use of sensitivity analysis in PBPK. We fully 8 96 10

\section{Conflicts of interest}

Amin Rostami-Hodjegan is an employee of Certara UK Limited (Simcyp Division).

\section{Acknowledgment}

The authors would like to thank Eleanor Savill for her assistance in the submission of the manuscript. 


\section{Tables}

Table 1: model parameter values.

\begin{tabular}{|c|c|c|c|}
\hline Parameter name & Value & Unit & Reference \\
\hline$B W$ : body weight & 70 & $\mathrm{~kg}$ & {$[33]$} \\
\hline$C O:$ cardiac output & 350.37 & $l / h$ & [34] \\
\hline$W_{l i v}:$ liver weight (fraction of $B W$ ) & $1.81(0.026)$ & $\mathrm{kg}$ & [33] \\
\hline $\begin{array}{l}V_{c} \text { : central compartment volume (for } \\
\text { models in Figures } 1 \mathrm{a} \text { and } 1 \mathrm{c} \text { ) a }\end{array}$ & 115.91 & $l$ & [17] \\
\hline$V_{\text {ent }}:$ volume of the enterocytes & 0.2242 & $l$ & [34] \\
\hline$Q_{\text {liv,art }}:$ liver blood flow (percentage of $\mathrm{CO}$ ) & $\begin{array}{l}68.32 \\
(0.195)\end{array}$ & $l / h$ & [33] \\
\hline $\begin{array}{l}Q_{\text {liv,ven }} \text { : hepatic vein blood flow (percentage } \\
\text { of }(O)\end{array}$ & $\begin{array}{l}89.34 \\
(0.255)\end{array}$ & $l / h$ & [33] \\
\hline$Q_{\text {ent }}:$ blood flow out of the enterocytes & 16.82 & $l / h$ & [34] \\
\hline $\begin{array}{l}k_{t} \text { : time constant relative to the transit in } \\
\text { the intestine }\end{array}$ & 0.3 & $h^{-1}$ & Calculated $^{\mathrm{d}}$ \\
\hline $\begin{array}{l}P_{\text {eff }} \text { : effective permeability across the gut } \\
\text { wall }^{\mathrm{b}}\end{array}$ & 8.70 & $10^{-4} \mathrm{~cm} / \mathrm{s}$ & [20] \\
\hline$\rho_{\text {liv }}:$ liver density ${ }^{\mathrm{c}}$ & 1.080 & $\mathrm{~kg} / \mathrm{l}$ & [35] \\
\hline $\begin{array}{l}f_{e w, l i v}: \text { fraction of extracellular water in } \\
\text { liver }\end{array}$ & 0.161 & - & [36] \\
\hline$f_{i w, l i v}$ : fraction of intracellular water in liver & 0.573 & - & [36] \\
\hline $\begin{array}{l}\text { MPPGL: milligram of microsomal proteins } \\
\text { per g of liver }\end{array}$ & 39.79 & $\mathrm{mg} \mathrm{prot} / \mathrm{g}$ liver & [18] \\
\hline HPGL: hepatocellularity per gram of liver & 117.52 & $10^{6}$ hepatocytes $/ g$ l & [18] \\
\hline
\end{tabular}

${ }^{a}$ Calculated as the median of the values in [17] times $B W(70 \mathrm{~kg})$ minus the liver volume.

$\mathrm{b}$ Taken equal to the maximum value in [20].

${ }^{\mathrm{c}}$ Used to calculate $V_{\text {liv }}$ from $W_{\text {liv }}: V_{\text {liv }}=W_{\text {liv }} / \rho_{\text {liv }}$.

${ }^{\mathrm{d}}$ Calculated dividing the minimum of the mean flow rate in the jejunum $(0.5 \mathrm{ml} / \mathrm{min})$ by the minimum volume $(100 \mathrm{~mL})$ reported in [37]. 
Table 2: parameters of the enzymatic distributions.

\begin{tabular}{|c|c|c|c|c|}
\hline Parameter name & $\begin{array}{l}\text { Distribution } \\
\text { parameters }\end{array}$ & $\begin{array}{l}\text { Distribution } \\
\text { type }\end{array}$ & Unit & Reference \\
\hline $\begin{array}{l}{[C Y P 3 A 4]_{m i c}:} \\
\text { CYP3A4 } \\
\text { microsomal } \\
\text { concentration }\end{array}$ & $137(41 \%)$ & Lognormal $^{\mathrm{a}}$ & $\mathrm{pmol} / \mathrm{mg}$ prot & [18] \\
\hline $\begin{array}{l}C Y P 3 A 4_{\text {ent }} \text { : total } \\
\text { amount of } \\
\text { CYP3A4 in small } \\
\text { intestine }\end{array}$ & $66.2(60 \%)$ & Lognormal $^{\mathrm{a}}$ & nmol & [18] \\
\hline $\begin{array}{l}{[C Y P 2 C 8]_{m i c}:} \\
\text { CYP2C8 } \\
\text { microsomal } \\
\text { concentration }\end{array}$ & $24(81 \%)$ & Lognormal $^{\text {a }}$ & $\mathrm{pmol} / \mathrm{mg}$ prot & [18] \\
\hline $\begin{array}{l}{[O A T P 1 B 1]_{\text {cells }}:} \\
\text { OATP } 1 \mathrm{~B} 1 \\
\text { concentration per } \\
10^{6} \text { cells }\end{array}$ & $4.28(74 \%)$ & Lognormal $^{\mathrm{a}}$ & pmol $/ 10^{6}$ hepatocytes & [18] \\
\hline
\end{tabular}

${ }^{\mathrm{a}}$ For distribution parameters, mean (coefficient of variation) of the lognormal random variable.

Table 3: repaglinide related parameters.

\begin{tabular}{|c|c|c|c|}
\hline Parameter name & Value & Unit & Reference \\
\hline$m w$ : molecular weight & 452.6 & $g / m o l$ & [8] \\
\hline$V_{\max , 3 A 4}{ }^{\mathrm{a}}$ & 958.2 & $\mathrm{pmol} / \mathrm{min} / \mathrm{mg}$ prot & [25] \\
\hline$K_{M, 3 A 4}$ & 13.2 & $\mu M$ & [25] \\
\hline$V_{\max , 2 C 8}{ }^{\mathrm{a}}$ & 300.8 & $\mathrm{pmol} / \mathrm{min} / \mathrm{mg}$ prot & [25] \\
\hline$K_{M, 2 C 8}$ & 2.3 & $\mu M$ & [25] \\
\hline $\begin{array}{l}C L_{\text {int }, O A T P}: \text { intrinsic } \\
\text { clearance of OATP }\end{array}$ & 246 & $\mu l / \mathrm{min} / 10^{6}$ hepatocytes & [8] \\
\hline$C L_{P S}:$ passive clearance & 0.089 & $\mathrm{ml} / \mathrm{min} / 10^{6}$ hepatocytes & [8] \\
\hline $\begin{array}{l}V_{s s}: \text { volume of } \\
\text { distribution at the steady } \\
\text { state }\end{array}$ & 0.24 & $l / k g$ & [8] \\
\hline $\begin{array}{l}f u_{t}: \text { fraction unbound in } \\
\text { liver tissue }\end{array}$ & 0.072 & - & {$[23,24]$} \\
\hline
\end{tabular}




\section{Figures captions}

Fig. 1 different models used in this study: a) intravenously administered drugs metabolised by two enzymes expressed in the liver; b) orally administered drugs metabolised by CYP3A4 expressed in the liver and gut wall; c) intravenously administered drugs metabolised by CYP3A4 and OATP1B1, both expressed in the liver; $d$ ) intravenous administration of repaglinide, a drug substrate of CYP3A4, CYP2C8 and OATP1B1

Fig. $2 R_{P}$ indices for the model in Figure 1a, computed for different inhibition levels and $C L_{\text {int }}$ values: a) $R_{P}$ indices for the $5^{\text {th }}$ percentile; b) $R_{P}$ indices for the median; c) $R_{P}$ indices for the $95^{\text {th }}$ percentile; d) $R_{p}$ indices for $5^{\text {th }}$ percentile, median and $95^{\text {th }}$ percentile in absence of inhibition. For central $C L_{\text {int }}$ values the AUC distribution is wider $\left(R_{P, 5}{ }^{t h}<0\right.$ and $\left.R_{P, 95^{t h}}>0\right)$ in case of correlation with respect to the absence of that

Fig. 3 ratio between $R_{\text {inh,corr }}$ and $R_{\text {inh,not corr }}$. It is possible to observe that in case of correlation the distribution of $\mathrm{R}_{\mathrm{inh} \text {,corr }}$ is narrower with respect to the one of $R_{\text {inh,not corr }}\left(95^{\text {th }}\right.$ percentile $<0$ and $5^{\text {th }}$ percentile $>0$ ). Moreover, it can be seen that the median of the ratios in case of correlation is equal to the one in case of absence of that

Fig. $4 R_{P}$ indices for the model in Figure 1b, computed for different inhibition levels and $C L_{\text {int }}$ values: a) $R_{P}$ indices for the $5^{\text {th }}$ percentile; b) $R_{P}$ indices for the median; c) $R_{P}$ indices for the $95^{\text {th }}$ percentile; d) $R_{p}$ indices for $5^{\text {th }}$ percentile, median and $95^{\text {th }}$ percentile in absence of inhibition. For higher $C L_{\text {int }}$ values the AUC distribution is wider $\left(R_{P, 5^{t h}}<0\right.$ and $\left.R_{P, 95^{t h}}>0\right)$ in case of correlation with respect to the absence of that

Fig. $55^{\text {th }}$ percentile, median and $95^{\text {th }}$ percentile of the fraction metabolized by the liver (panel a) and the gut wall (panel b) distributions for different values of $C L_{\text {int }}$, in case of absence of inhibition, predicted by using the model in Figure 1b. It is possible to observe that the percentiles of the fraction metabolized by the gut wall distributions are equal in case of presence and absence of correlation. This result is trivial because the fraction metabolized by the gut wall depend only on the CYP3A4 expression in that site. Moreover, it is possible to observe that the two yellow median lines overlap in both panel $\mathrm{a}$ and $\mathrm{b}$ 
Fig. 6 ratio between the bioavailability in presence and absence of inhibition of both CYP3A4 gut wall and liver clearance ( $I=0$ and $I=1$, respectively), predicted by using the model in Figure $1 \mathrm{~b}$ and calculated for different values of $C L_{\text {int }}$. Continuous and dashed lines represent the various percentiles $\left(5^{\text {th }}, 50^{\text {th }}\right.$ and $\left.95^{\text {th }}\right)$ in absence and presence of correlation between CYP3A4 in gut wall and in liver

Fig. $7 R_{p}$ indices for the model in Figure 1c, computed for different levels of CYP3A4 and OATP1B1 intrinsic clearances: a) $R_{p}$ indices for the $5^{\text {th }}$ percentile; b) $R_{p}$ indices for the median; c) $R_{p}$ indices for the $95^{\text {th }}$ percentile; d) $R_{p}$ indices in function of CYP3A4 intrinsic clearance for the $10^{\text {th }}$ entry (out of 20) of OATP1B1 intrinsic clearance vector. For central $C L_{\text {int }}$ values the AUC distribution is wider $\left(R_{P, 5}{ }^{t h}<0\right.$ and $\left.R_{P, 95}{ }^{t h}>0\right)$ in case of correlation with respect to the absence of that

Fig. 8 main and total effect of CYP3A4, CYP2C8 and OATP1B1 concentrations, for different correlation levels between CYP3A4 and CYP2C8, for the model in Figure 1d. Indices corresponding to the physiological $\rho$ are highlighted in red. To deal with the correlation between the two enzymatic concentrations, here CYP2C8 was expressed as a function of CYP3A4 by using a linear regression plus the addition of a noise. Error bars represent the standard deviation of the estimated sensitivity indices

Fig. 9 main and total effect of CYP3A4, CYP2C8 and OATP1B1 concentrations, in case of absence and presence of a physiological correlation between the expression of CYP3A4 and CYP2C8, for the model in Figure 1d. To deal with the correlation between the two enzymatic concentrations, here CYP2C8 was expressed as a function of CYP3A4 by using a linear regression plus the addition of a noise. Error bars represent the standard deviation of the estimated sensitivity indices

Fig. 10 main and total effect of CYP3A4, CYP2C8 and OATP1B1 concentrations, for different correlation levels between CYP3A4 and CYP2C8, for the model in Figure 1d. Indices corresponding to the physiological $\rho$ are highlighted in red. To deal with the correlation between the two enzymatic concentrations, here CYP3A4 was expressed as a function of CYP2C8 by using a linear regression plus the addition of a noise. Error bars represent the standard deviation of the estimated sensitivity indices 


\section{A. Appendix}

The differential equations of the model represented in Figure $1 \mathrm{~b}$ are reported in (5). The model describes the bioavailability of a generic drug following oral administration. Our purpose was to derive analytically the expression of the $F_{\text {oral }}$ following a bolus in the compartment representing the small intestine.

The solution of $x_{\text {lum }}$ is the one of a single compartment with two linear clearances, so:

$$
x_{\text {lum }}=D_{0} e^{-\left(k_{t}+k_{a}\right) t}
$$

with $D_{0}$ the dose. It is possible to substitute the expression of $x_{\text {lum }}$ in the equation representing the dynamics of $x_{\text {ent }}$ in the equation system (5). By multiplying $\exp \left(\left(Q_{\text {ent }}+C L_{\text {ent }}\right) / V_{\text {ent }} \cdot t\right)$ in both the sides of that equation, is possible to derive the expressions below and thus the analytical solution of $x_{\text {ent }}$.

$$
\begin{gathered}
\frac{d}{d t}\left(x_{\text {ent }} e^{\left(\frac{Q_{\text {ent }}}{V_{\text {ent }}}+\frac{C L_{\text {ent }}}{V_{\text {ent }}}\right) t}\right)=D_{0} k_{a} e^{\left(-\left(k_{t}+k_{a}\right) t+\left(\frac{Q_{\text {ent }}}{V_{\text {ent }}}+\frac{C L_{\text {ent }}}{V_{\text {ent }}}\right) t\right)} \\
x_{\text {ent }} e^{\left(\frac{Q_{e n t}}{V_{\text {ent }}}+\frac{C L_{\text {ent }}}{V_{\text {ent }}}\right) t}=D_{0} k_{a} \int_{0}^{t} e^{\left(-\left(k_{t}+k_{a}\right) t+\left(\frac{Q_{e n t}}{V_{\text {ent }}}+\frac{C L_{\text {ent }}}{V_{\text {ent }}}\right) t\right)} d t \\
x_{\text {ent }}=\frac{D_{0} k_{a}}{\left(\frac{Q_{\text {ent }}}{V_{\text {ent }}}+\frac{C L_{\text {ent }}}{V_{\text {ent }}}\right)-\left(k_{t}+k_{a}\right)}\left[e^{-\left(k_{t}+k_{a}\right)}-e^{-\left(\frac{Q_{\text {ent }}}{V_{\text {ent }}}+\frac{C L_{\text {ent }}}{V_{\text {ent }}}\right) t}\right]
\end{gathered}
$$

For readability purpose, let us define the following variables.

$$
\begin{gathered}
k_{\text {lum }}=\left(k_{t}+k_{a}\right), k_{\text {ent }}= \\
\left(\frac{Q_{\text {ent }}}{V_{\text {ent }}}+\frac{C L_{\text {ent }}}{V_{\text {ent }}}\right), k_{\text {liv }}=\left(\frac{Q_{\text {liv }, \text { ven }}}{V_{\text {liv }}}+\frac{C L_{\text {liv }}}{V_{\text {liv }}}\right) \\
\psi_{1}=\frac{D_{0} k_{a}}{k_{\text {ent }}-k_{\text {lum }}}
\end{gathered}
$$

Now, by substituting the $x_{\text {ent }}$ expression in $x_{\text {liv }}$ differential equation and multiplying both equation sides for $\exp \left(k_{l i v} \cdot t\right)$, is possible to derive the analytical solution of $x_{\text {liv }}$.

$$
\begin{gathered}
\frac{d}{d t}\left(x_{\text {liv }} e^{\left(k_{\text {liv }} t\right)}\right)=\frac{Q_{\text {ent }}}{V_{\text {ent }}} \psi_{1}\left(e^{\left(-k_{\text {lum }} t+k_{\text {liv }} t\right)}-e^{\left(-k_{\text {ent }} t+k_{\text {liv }} t\right)}\right) \\
x_{\text {liv }} e^{k_{\text {liv }} t}=\frac{Q_{\text {ent }}}{V_{\text {ent }}} \psi_{1} \int_{0}^{t}\left(e^{\left(-k_{\text {lum }} t+k_{\text {liv }} t\right)}-e^{\left(-k_{\text {ent }} t+k_{\text {liv }} t\right)}\right) d t \\
x_{\text {liv }}=\frac{Q_{\text {ent }}}{V_{\text {ent }}} \psi_{1}\left[\frac{1}{k_{\text {liv }}-k_{\text {lum }}}\left(e^{-k_{\text {lum }} t}-e^{-k_{\text {liv }} t}\right)-\frac{1}{k_{\text {liv }}-k_{\text {ent }}}\left(e^{-k_{\text {ent }} t}-e^{-k_{\text {liv }} t}\right)\right]
\end{gathered}
$$

Now, by substituting $x_{\text {liv }}$ in the last differential equation of system (5), is possible to derive directly the analytical solution of $x_{\text {sys }}$. 


$$
\begin{aligned}
& { }_{2}^{1} 1 \quad x_{\text {sys }}=\frac{Q_{\text {liv }, \text { ven }}}{V_{\text {liv }}} \frac{Q_{\text {ent }}}{V_{\text {ent }}} \psi_{1} \int_{0}^{t}\left[\frac{1}{k_{\text {liv }}-k_{\text {lum }}}\left(e^{-k_{\text {lum }} t}-e^{-k_{\text {liv }} t}\right)-\frac{1}{k_{\text {liv }}-k_{\text {ent }}}\left(e^{-k_{\text {ent }} t}-e^{-k_{\text {liv }} t}\right)\right] d t \\
& x_{\text {sys }}=\frac{Q_{\text {liv } v \text { ven }}}{V_{\text {liv }}} \frac{Q_{\text {ent }}}{V_{\text {ent }}} \psi_{1}\left[\frac{1}{k_{\text {liv }}-k_{\text {lum }}}\left(\frac{1}{k_{\text {lum }}}\left(1-e^{-k_{\text {lum }} t}\right)-\frac{1}{k_{\text {liv }}}\left(1-e^{-k_{\text {liv }} t}\right)\right)\right. \\
& \left.-\frac{1}{k_{\text {liv }}-k_{\text {ent }}}\left(\frac{1}{k_{\text {ent }}}\left(1-e^{-k_{\text {ent }} t}\right)-\frac{1}{k_{\text {liv }}}\left(1-e^{-k_{\text {liv }} t}\right)\right)\right]
\end{aligned}
$$




\section{References}

1. CHMP (EMA) (2016) Guideline on the qualification and reporting of physiologically based pharmacokinetic (PBPK) modelling and simulation - draft. Committee for Medicinal Products for Human Use (CHMP), European Medicines Agency (EMA), London, UK

2. McNally K, Cotton R, Hogg A, Loizou G (2015) Reprint of PopGen: A virtual human population generator. Toxicology 332:77-93. https://doi.org/10.1016/j.tox.2015.04.014

3. Willmann S, Höhn K, Edginton A, et al (2007) Development of a Physiology-Based WholeBody Population Model for Assessing the Influence of Individual Variability on the Pharmacokinetics of Drugs. J Pharmacokinet Pharmacodyn 34:401-431. https://doi.org/10.1007/s10928-007-9053-5

4. Rostami- Hodjegan A (2018) Reverse Translation in PBPK and QSP: Going Backwards in Order to Go Forward With Confidence. Clinical Pharmacology \& Therapeutics 103:224-232. https://doi.org/10.1002/cpt.904

5. Tsamandouras N, Wendling T, Rostami-Hodjegan A, et al (2015) Incorporation of stochastic variability in mechanistic population pharmacokinetic models: handling the physiological constraints using normal transformations. J Pharmacokinet Pharmacodyn 42:349-373. https://doi.org/10.1007/s10928-015-9418-0

6. Jamei M, Dickinson GL, Rostami-Hodjegan A (2009) A Framework for Assessing Interindividual Variability in Pharmacokinetics Using Virtual Human Populations and Integrating General Knowledge of Physical Chemistry, Biology, Anatomy, Physiology and Genetics: A Tale of 'Bottom-Up' vs 'Top-Down' Recognition of Covariates. Drug Metabolism and Pharmacokinetics 24:53-75. https://doi.org/10.2133/dmpk.24.53

7. Al Feteisi H, Achour B, Rostami-Hodjegan A, Barber J (2015) Translational value of liquid chromatography coupled with tandem mass spectrometry-based quantitative proteomics for in vitro-in vivo extrapolation of drug metabolism and transport and considerations in selecting appropriate techniques. Expert Opinion on Drug Metabolism \& Toxicology 11:1357-1369. https://doi.org/10.1517/17425255.2015.1055245

8. Doki Kosuke, Darwich Adam S., Achour Brahim, et al (2018) Implications of intercorrelation between hepatic CYP3A4- CYP2C8 enzymes for the evaluation of drug-drug interactions: a case study with repaglinide. British Journal of Clinical Pharmacology 84:972-986. https://doi.org/10.1111/bcp.13533

9. Achour B, Russell MR, Barber J, Rostami-Hodjegan A (2014) Simultaneous Quantification of the Abundance of Several Cytochrome P450 and Uridine 5'-DiphosphoGlucuronosyltransferase Enzymes in Human Liver Microsomes Using Multiplexed Targeted Proteomics. Drug Metab Dispos 42:500-510. https://doi.org/10.1124/dmd.113.055632

10. von Richter O, Burk O, Fromm MF, et al (2004) Cytochrome P450 3A4 and P-glycoprotein Expression in Human Small Intestinal Enterocytes and Hepatocytes: A Comparative Analysis in Paired Tissue Specimens. Clinical Pharmacology \& Therapeutics 75:172-183. https://doi.org/10.1016/j.clpt.2003.10.008

11. Drozdzik M, Busch D, Lapczuk J, et al (2017) Protein Abundance of Clinically Relevant Drug-Metabolizing Enzymes in the Human Liver and Intestine: A Comparative Analysis in 
Paired Tissue Specimens. Clinical Pharmacology \& Therapeutics 0: https://doi.org/10.1002/cpt.967

12. Saltelli A, Tarantola S, Campolongo F, Ratto M (2004) Sensitivity Analysis in Practice: A Guide to Assessing Scientific Models. John Wiley \& Sons, Ltd

13. Saltelli A, Ratto M, Andres T, et al (2008) Global Sensitivity Analysis. The Primer. John Wiley \& Sons, Ltd

14. Saltelli A (2002) Making best use of model evaluations to compute sensitivity indices. Computer Physics Communications 145:280-297. https://doi.org/10.1016/S00104655(02)00280-1

15. Sobol IM (1993) Sensitivity Estimates for Nonlinear Mathematical Models. Mathematical modelling and computational experiments 1:407-414

16. (2017) MATLAB R2017b. The MahWorks, Inc., Natick, Massachusetts, United States

17. Jones RD, Jones HM, Rowland M, et al (2011) PhRMA CPCDC initiative on predictive models of human pharmacokinetics, part 2: Comparative assessment of prediction methods of human volume of distribution. Journal of Pharmaceutical Sciences 100:4074-4089. https://doi.org/10.1002/jps.22553

18. (2017) Simcyp Simulator - Version 17. CERTARA, L. P., Sheffield, UK

19. Bu H-Z (2006) A Literature Review of Enzyme Kinetic Parameters for CYP3A4-Mediated Metabolic Reactions of 113 Drugs in Human Liver Microsomes: Structure- Kinetics Relationship Assessment. Current Drug Metabolism 7:231-249. https://doi.org/10.2174/138920006776359329

20. Lennernäs H (2014) Human in Vivo Regional Intestinal Permeability: Importance for Pharmaceutical Drug Development. Mol Pharmaceutics 11:12-23.

https://doi.org/10.1021/mp4003392

21. Jamei M, Marciniak S, Edwards D, et al (2013) The Simcyp Population Based Simulator: Architecture, Implementation, and Quality Assurance. In Silico Pharmacol 1:9. https://doi.org/10.1186/2193-9616-1-9

22. Shitara Y, Maeda K, Ikejiri K, et al (2013) Clinical significance of organic anion transporting polypeptides (OATPs) in drug disposition: their roles in hepatic clearance and intestinal absorption. Biopharmaceutics \& Drug Disposition 34:45-78. https://doi.org/10.1002/bdd.1823

23. Gertz M, Tsamandouras N, Säll C, et al (2014) Reduced Physiologically-Based Pharmacokinetic Model of Repaglinide: Impact of OATP1B1 and CYP2C8 Genotype and Source of In Vitro Data on the Prediction of Drug-Drug Interaction Risk. Pharm Res 31:23672382. https://doi.org/10.1007/s11095-014-1333-3

24. Ménochet K, Kenworthy KE, Houston JB, Galetin A (2012) Simultaneous Assessment of Uptake and Metabolism in Rat Hepatocytes: A Comprehensive Mechanistic Model. J Pharmacol Exp Ther 341:2-15. https://doi.org/10.1124/jpet.111.187112 
25. Kajosaari LI, Laitila J, Neuvonen PJ, Backman JT (2005) Metabolism of Repaglinide by CYP2C8 and CYP3A4 in vitro: Effect of Fibrates and Rifampicin. Basic \& Clinical Pharmacology \& Toxicology 97:249-256. https://doi.org/10.1111/j.1742-7843.2005.pto_157.x

26. Couto N, Al-Majdoub ZM, Achour B, et al (2019) Quantification of Proteins Involved in Drug Metabolism and Disposition in the Human Liver Using Label-Free Global Proteomics. Mol Pharmaceutics 16:632-647. https://doi.org/10.1021/acs.molpharmaceut.8b00941

27. Greenblatt DJ, Moltke LL von, Harmatz JS, et al (2003) Time course of recovery of cytochrome p450 3A function after single doses of grapefruit juice. Clinical Pharmacology \& Therapeutics 74:121-129. https://doi.org/10.1016/S0009-9236(03)00118-8

28. Da Veiga S, Wahl F, Gamboa F (2009) Local Polynomial Estimation for Sensitivity Analysis on Models With Correlated Inputs. Technometrics 51:452-463. https://doi.org/10.1198/TECH.2009.08124

29. Li G, Rabitz H, Yelvington PE, et al (2010) Global Sensitivity Analysis for Systems with Independent and/or Correlated Inputs. J Phys Chem A 114:6022-6032. https://doi.org/10.1021/jp9096919

30. Saltelli A, Tarantola S (2002) On the Relative Importance of Input Factors in Mathematical Models: Safety Assessment for Nuclear Waste Disposal. Journal of the American Statistical Association 97:702-709

31. Xu C, Gertner G (2007) Extending a global sensitivity analysis technique to models with correlated parameters. Computational Statistics \& Data Analysis 51:5579-5590. https://doi.org/10.1016/j.csda.2007.04.003

32. Iooss B, Lemaitre P (2015) A review on global sensitivity analysis methods. In: Meloni C, Dellino G (eds) Uncertainty management in Simulation-Optimization of Complex Systems: Algorithms and Applications. Springer

33. Valetin J (2002) Basic Anatomical and Physiological Data for Use in Radiological Protection: Reference Values. International Commission on Radiological Protection (ICRP)

34. Olivares-Morales A, Ghosh A, Aarons L, Rostami-Hodjegan A (2016) Development of a Novel Simplified PBPK Absorption Model to Explain the Higher Relative Bioavailability of the OROS® Formulation of Oxybutynin. AAPS J 18:1532-1549. https://doi.org/10.1208/s12248-016-9965-3

35. Brown RP, Delp MD, Lindstedt SL, et al (1997) Physiological Parameter Values for Physiologically Based Pharmacokinetic Models. Toxicol Ind Health 13:407-484. https://doi.org/10.1177/074823379701300401

36. Rodgers T, Leahy D, Rowland M (2005) Physiologically Based Pharmacokinetic Modeling 1: Predicting the Tissue Distribution of Moderate-to-Strong Bases. Journal of Pharmaceutical Sciences 94:1259-1276. https://doi.org/10.1002/jps.20322

37. Dressman JB, Fleisher D (1986) Mixing-Tank Model for Predicting Dissolution Rate Control of Oral Absorption. JPharmSci 75:109-116. https://doi.org/10.1002/jps.2600750202 
a

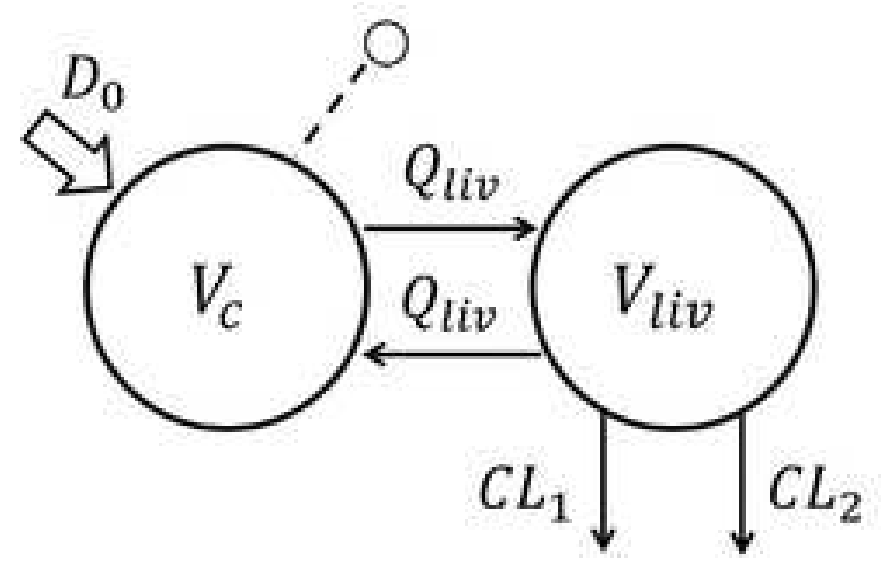

c

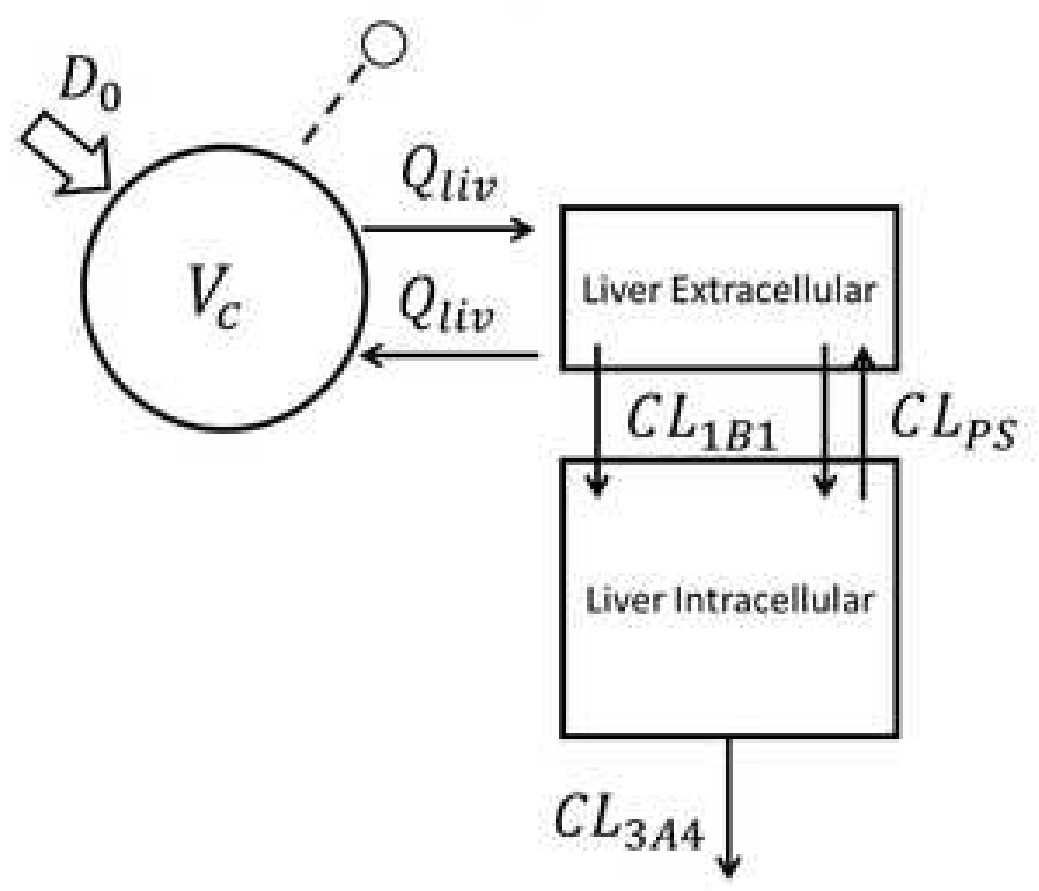

b
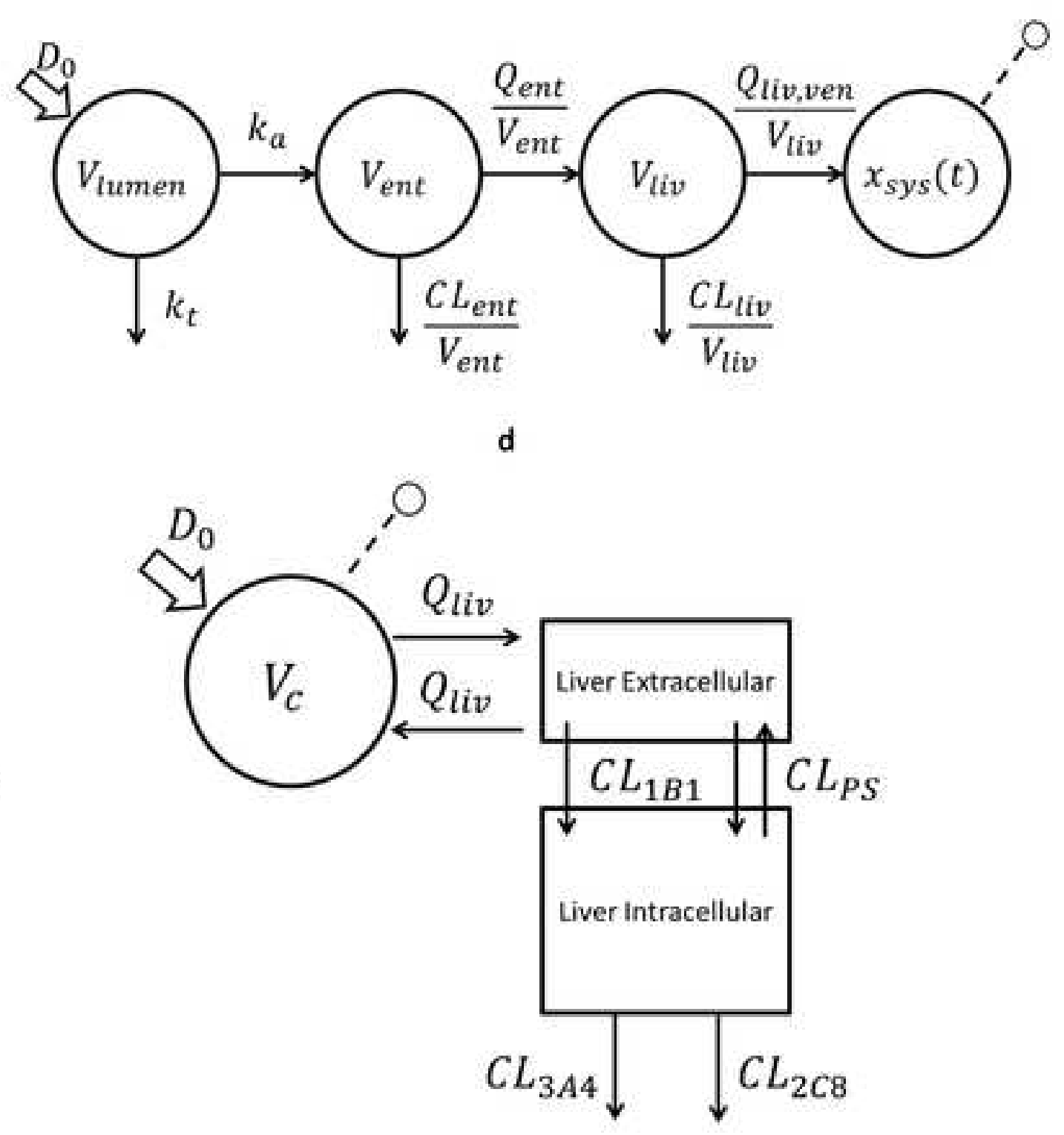
a) $R_{p} 5^{\text {th }}$ percentile

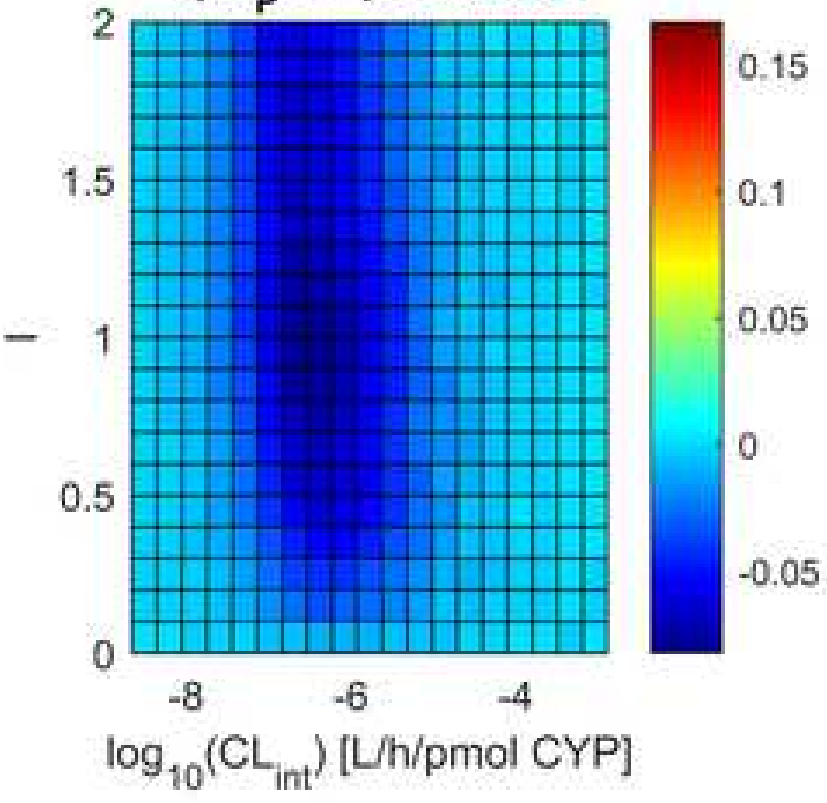

c) $R_{p} 95^{\text {th }}$ percentile

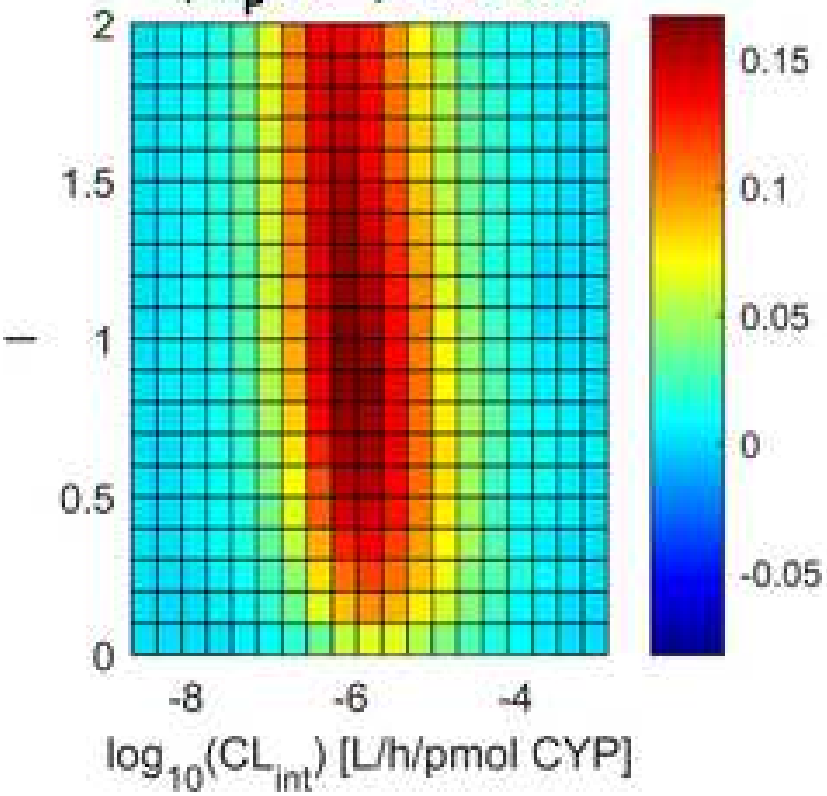

b) $R_{P}$ median
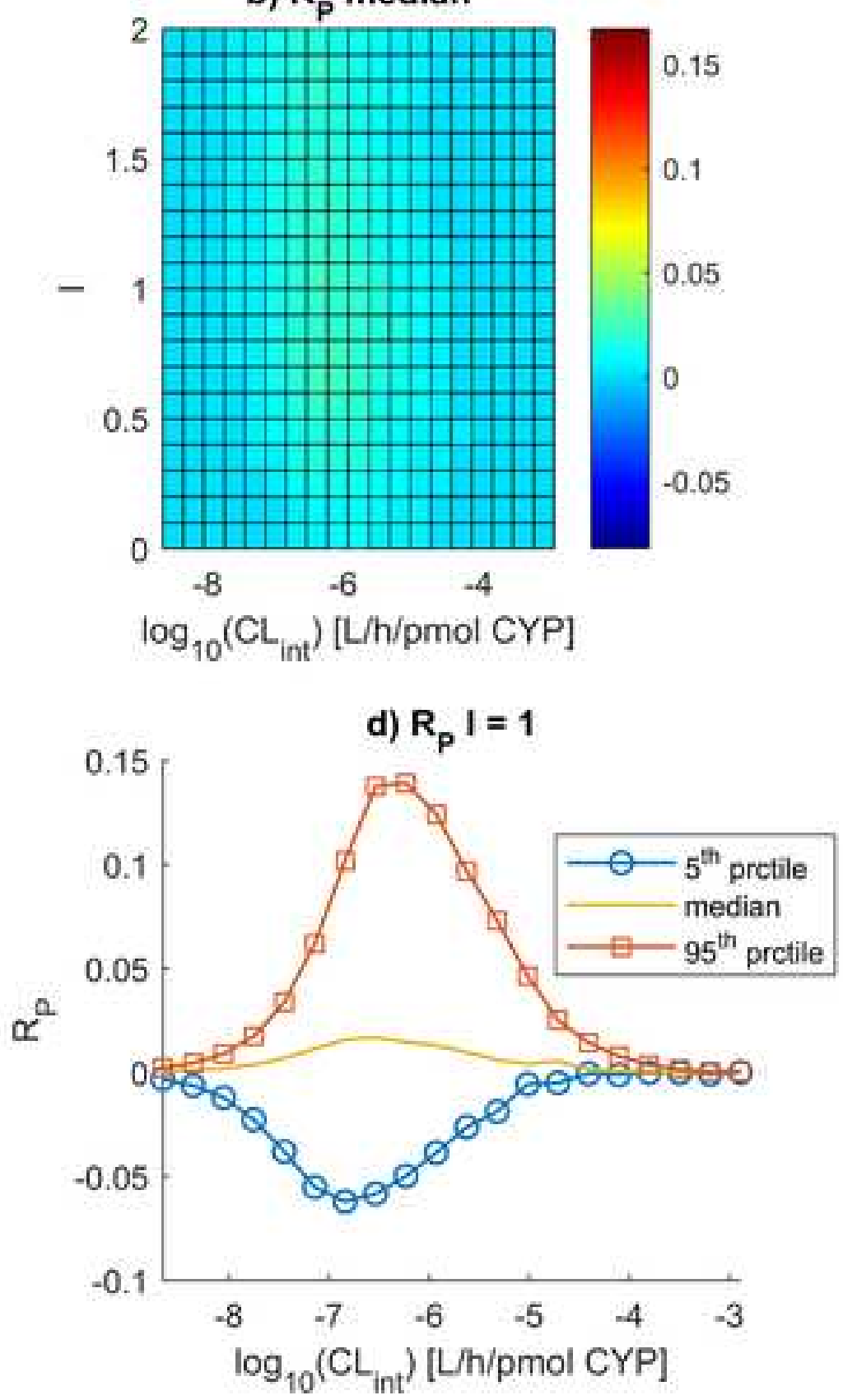


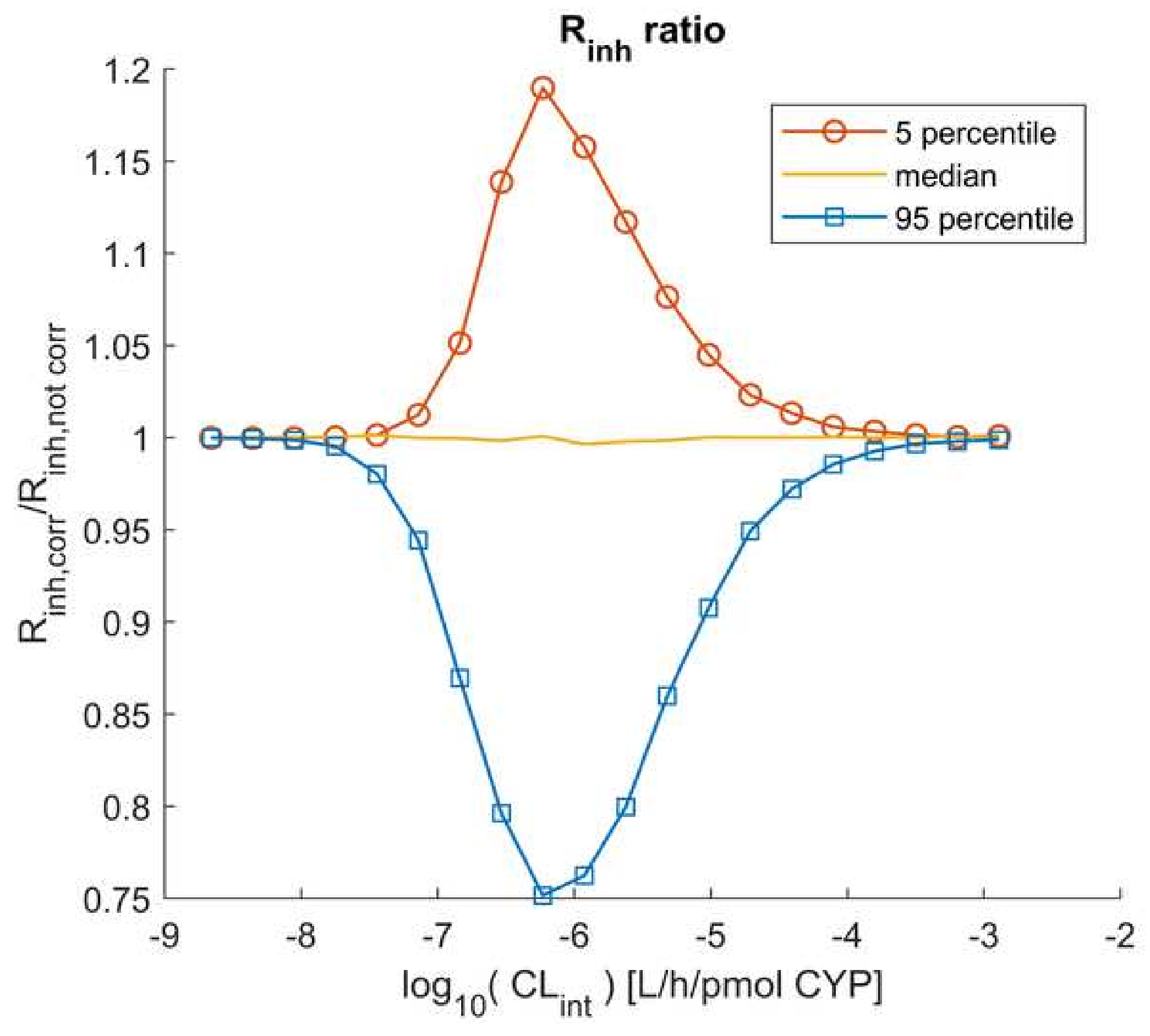




\section{a) $R_{p} 5^{\text {th }}$ percentile}

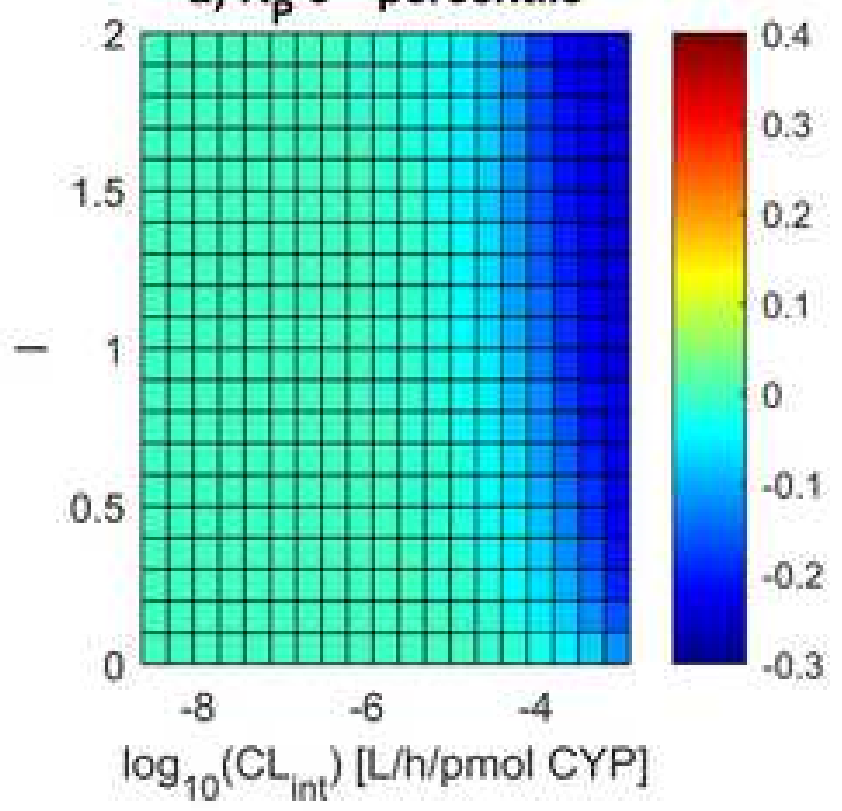

c) $R_{p} 95^{\text {th }}$ percentile

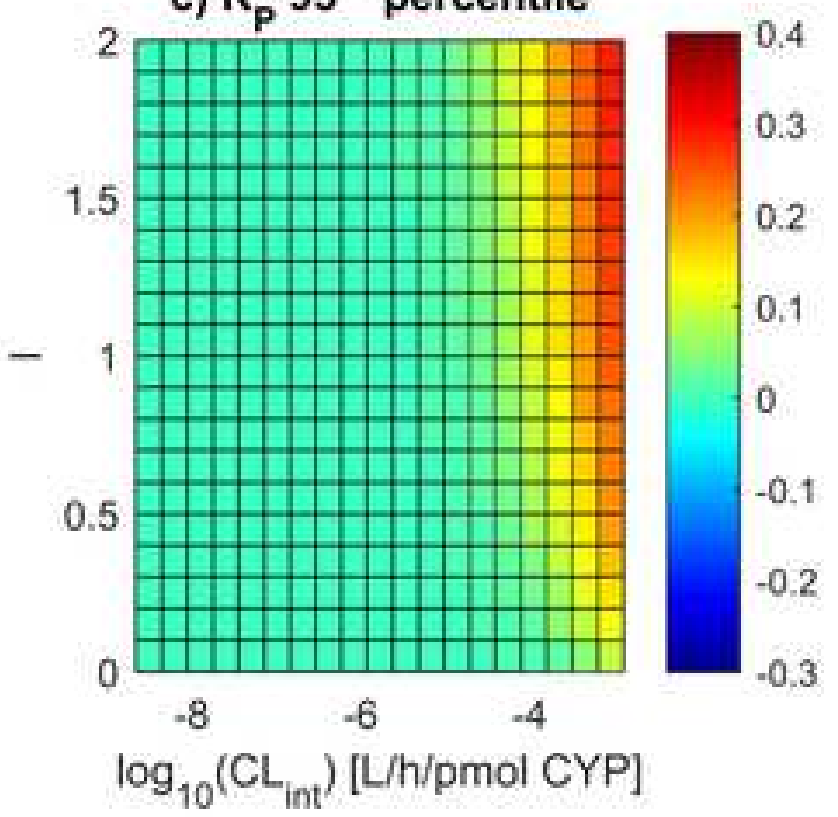

b) $\mathbf{R}_{\mathbf{p}}$ median
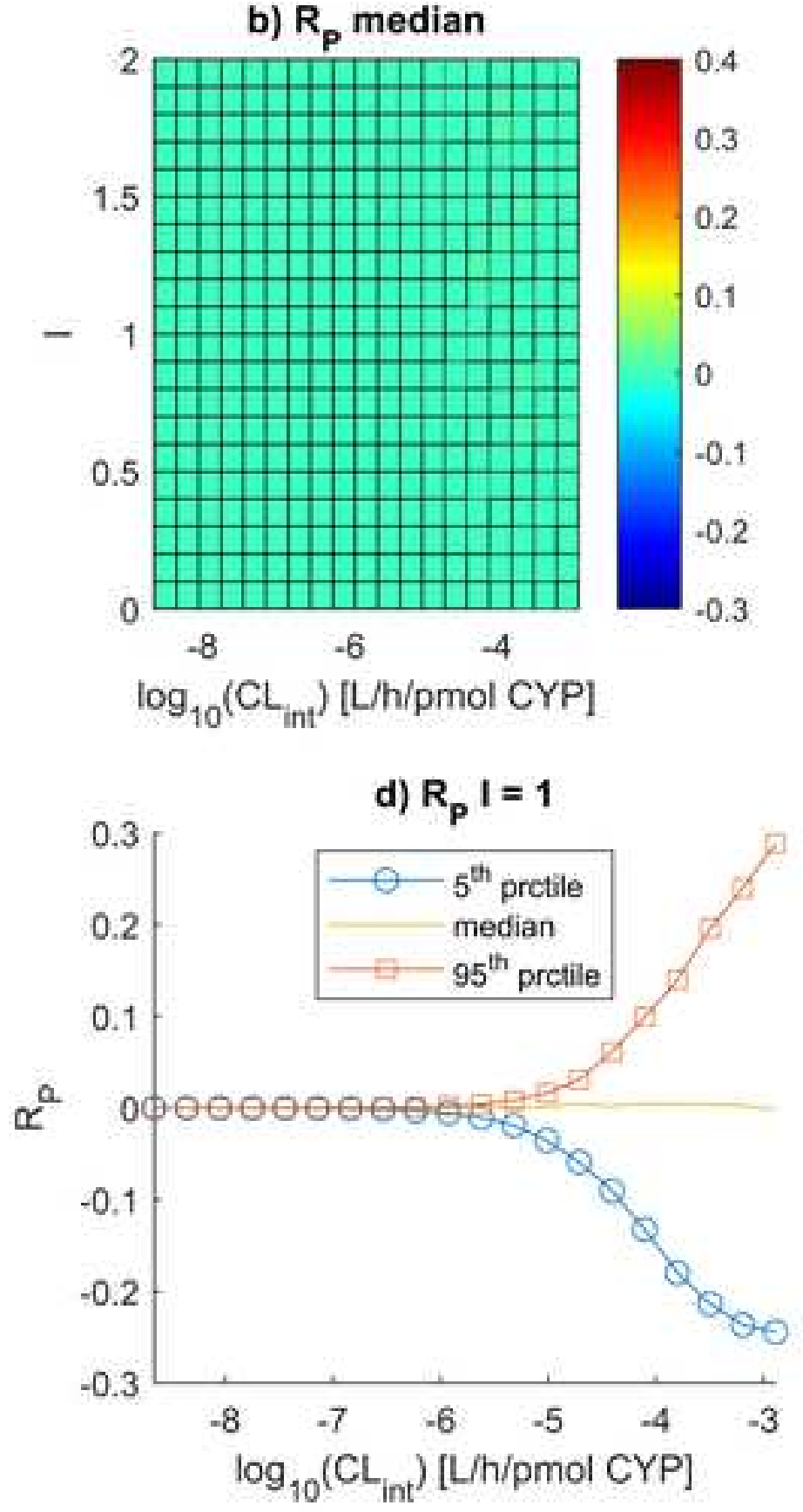

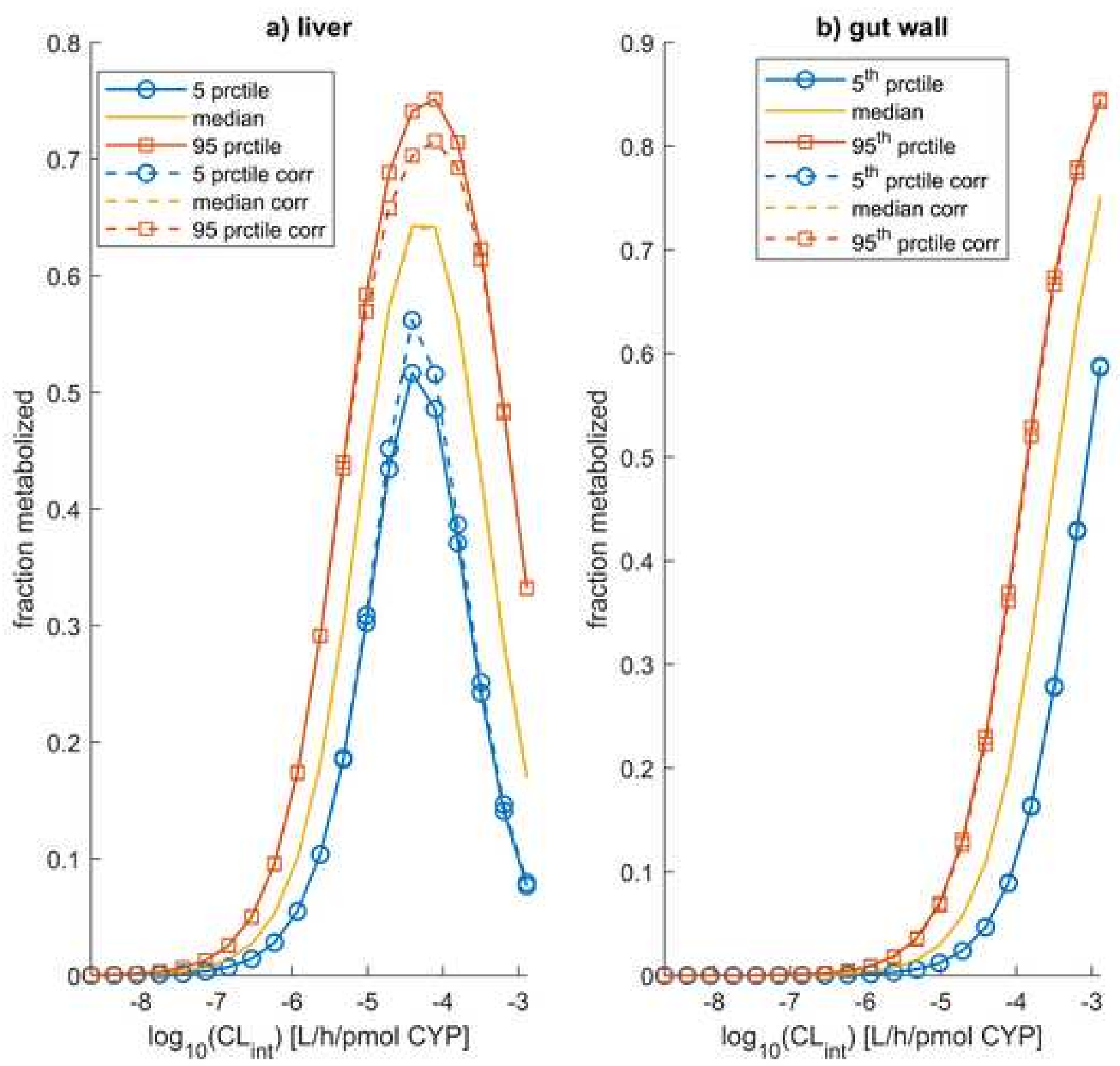


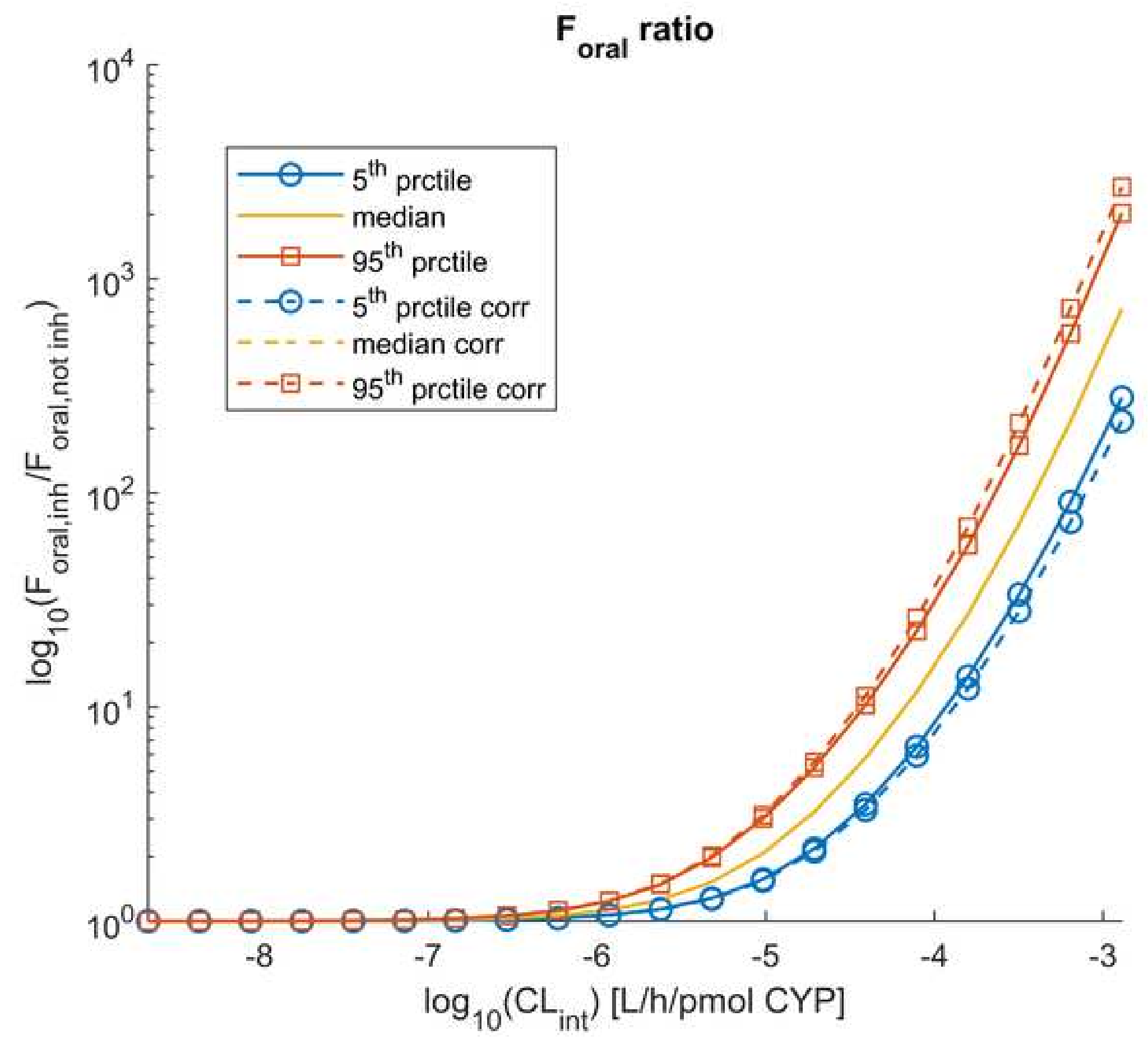


a) $R_{P} 5^{\text {th }}$ percentile

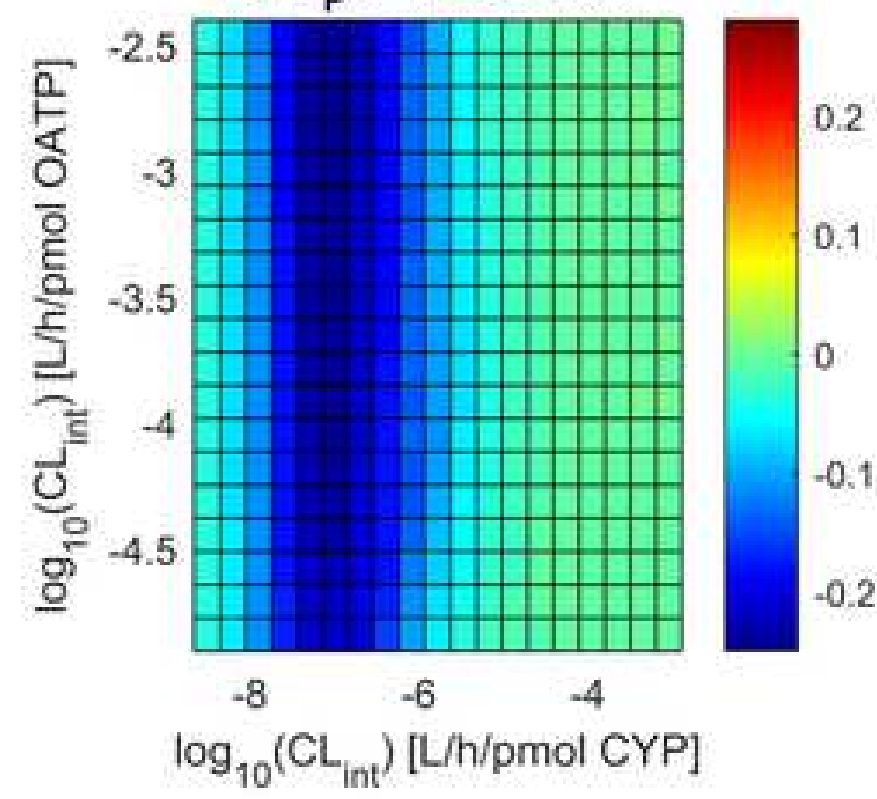

c) $R_{p} 95^{\text {th }}$ percentile

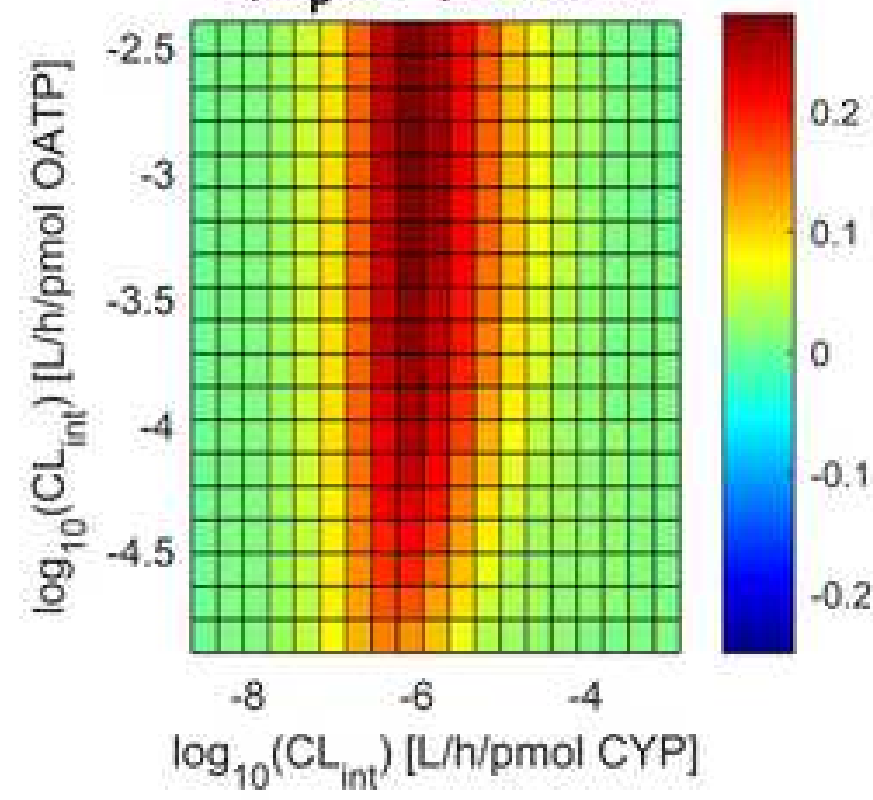

b) $R_{p}$ median
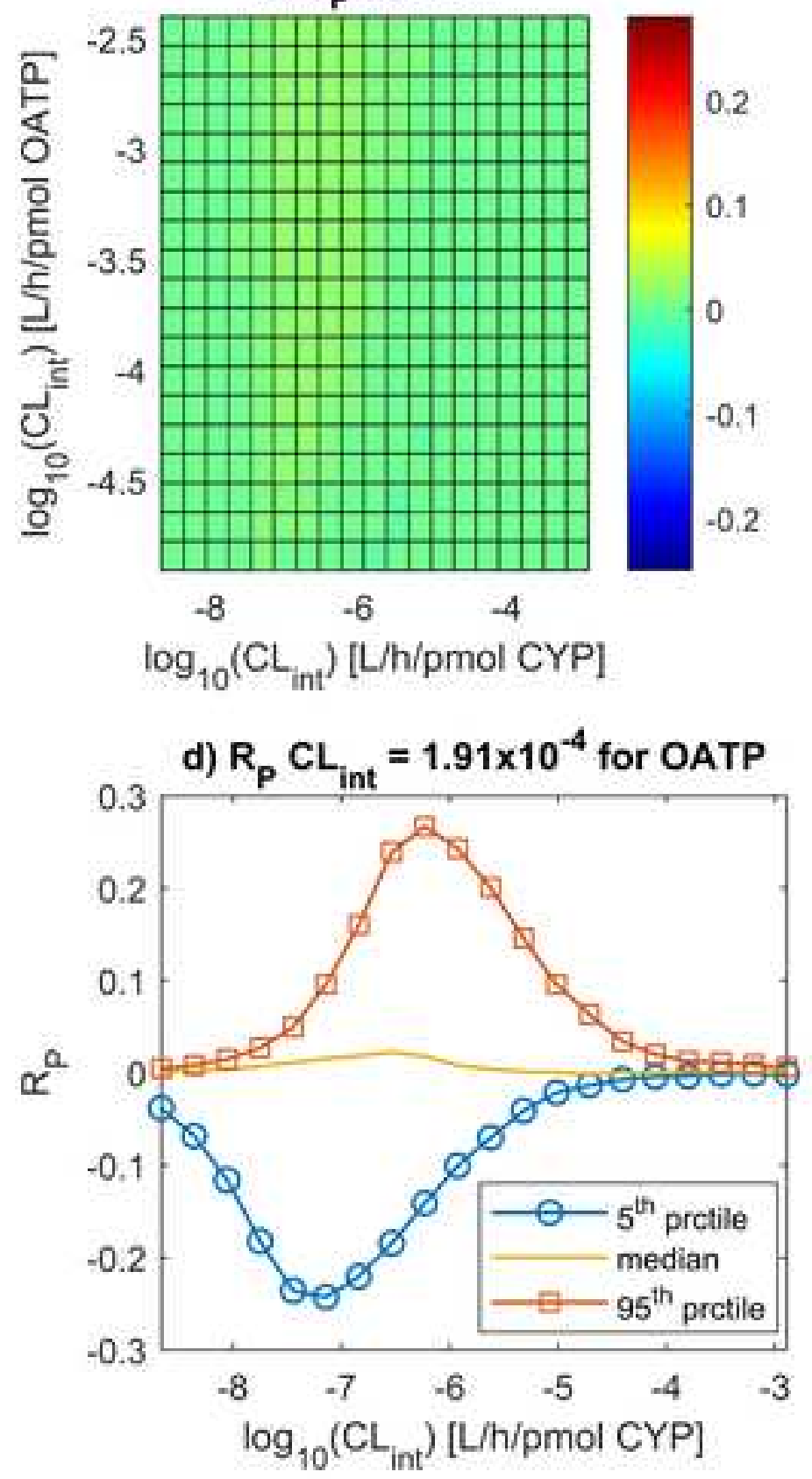


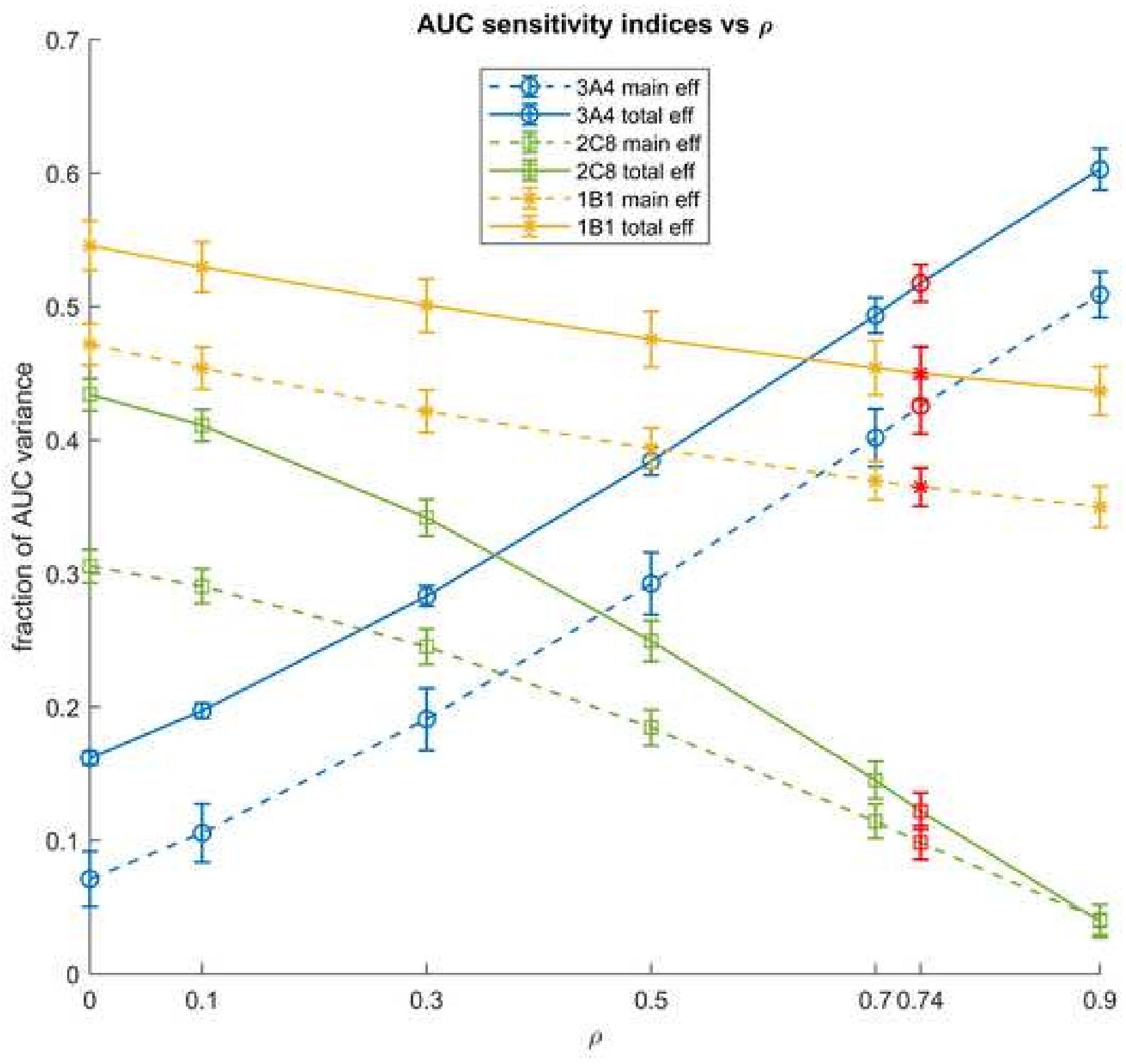




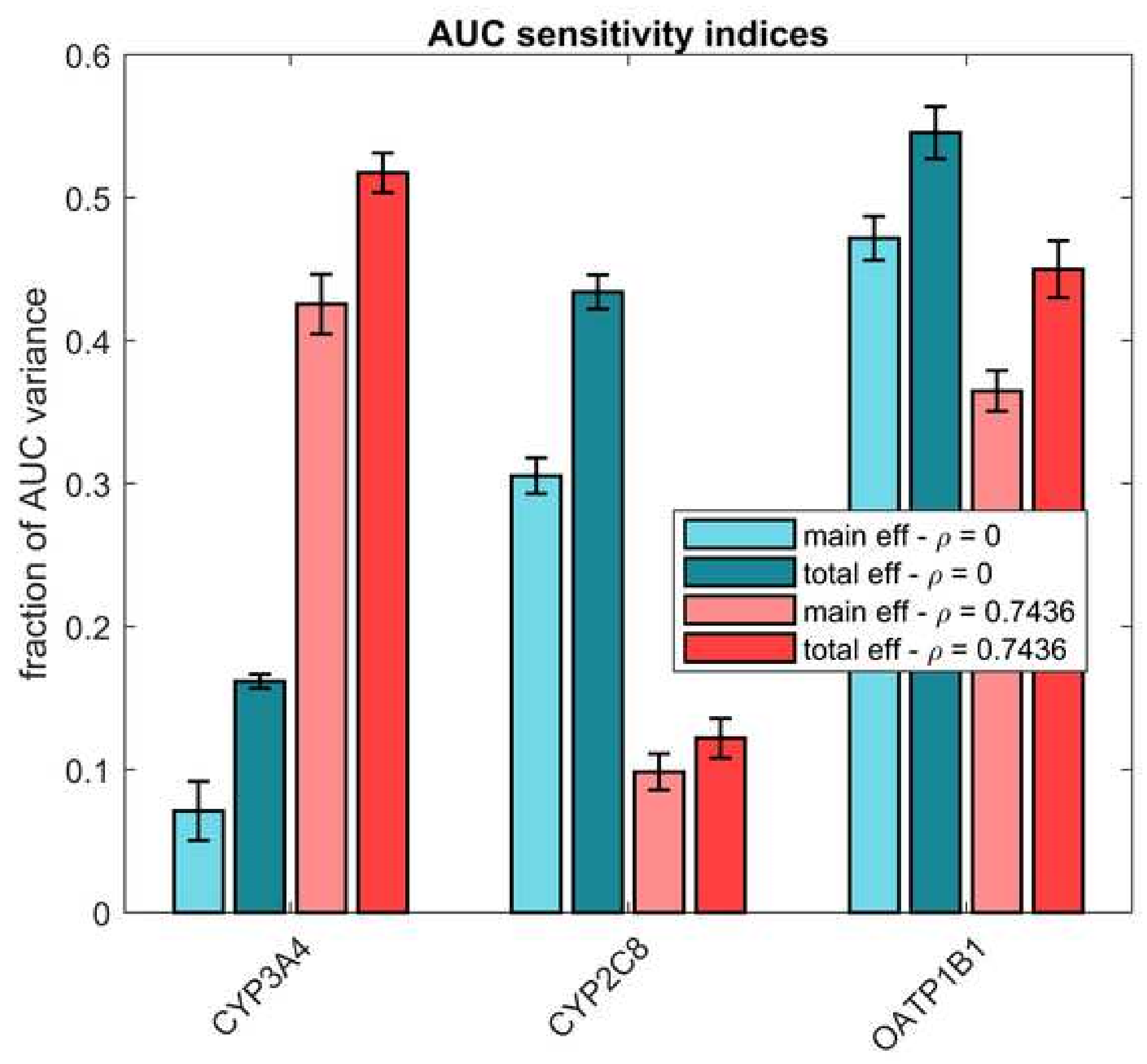




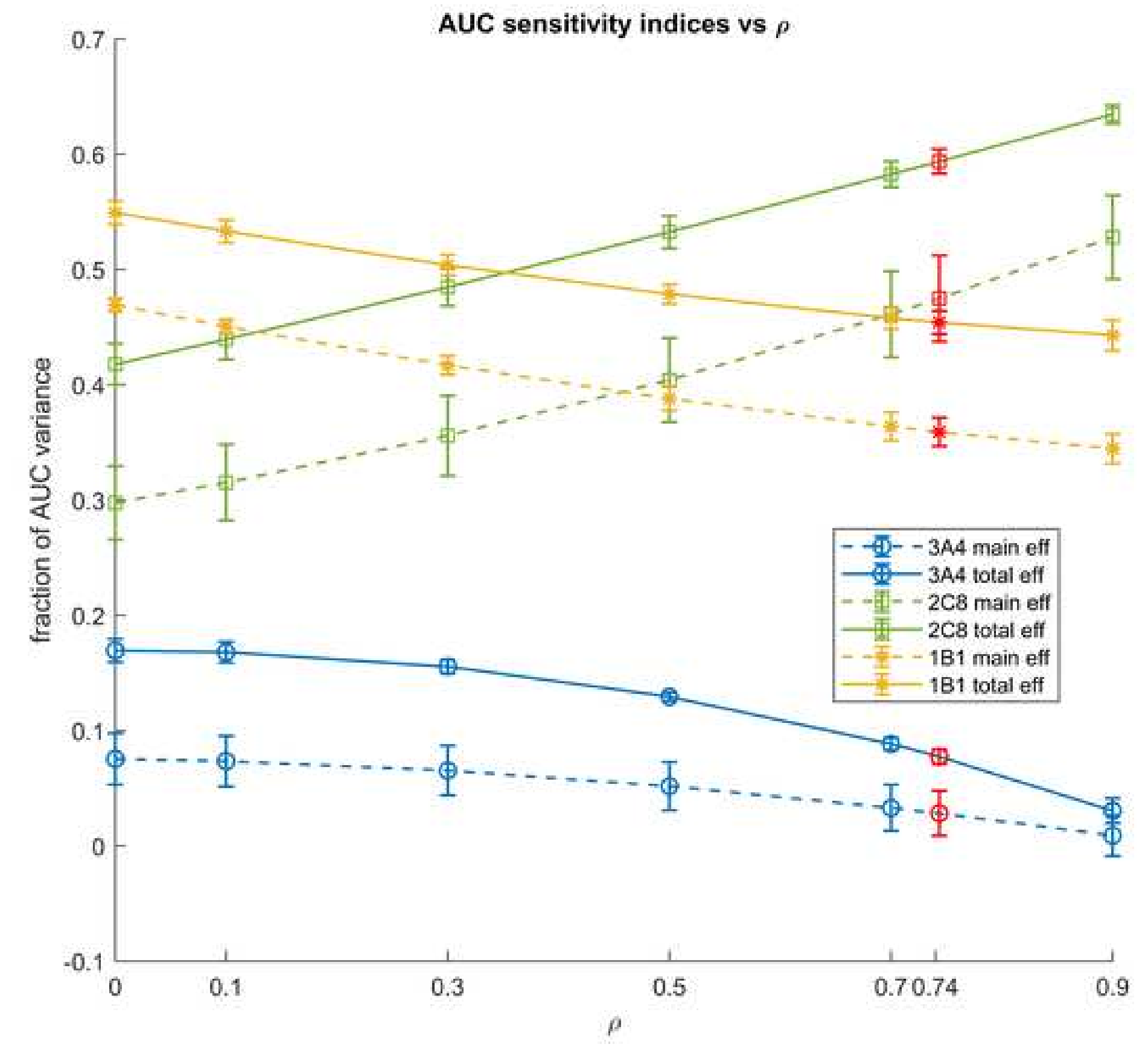

AUC sensitivity indices vs $\rho$ 